\section{Carotenoids co-localize with hydroxyapatite, cholesterol, and other lipids in calcified stenotic aortic valves. Ex vivo Raman maps compared to histological patterns}

\author{
A. Bonetti, ${ }^{1}$ A. Bonifacio, ${ }^{2}$ A. Della Mora, \\ U. Livi, ${ }^{1}$ M. Marchini, ${ }^{1}$ F. Ortolani ${ }^{1}$ \\ 'Department of Experimental \\ and Clinical Medicine, \\ University of Udine \\ 2Department of Engineering and \\ Architecture, University of Trieste, Italy
}

\begin{abstract}
Unlike its application for atherosclerotic plaque analysis, Raman microspectroscopy was sporadically used to check the sole nature of bioapatite deposits in stenotic aortic valves, neglecting the involvement of accumulated lipids/lipoproteins in the calcific process. Here, Raman microspectroscopy was employed for examination of stenotic aortic valve leaflets to add information on nature and distribution of accumulated lipids and their correlation with mineralization in the light of its potential precocious diagnostic use. Cryosections from surgically explanted stenotic aortic valves $(n=4)$ were studied matching Raman maps against specific histological patterns. Raman maps revealed the presence of phospholipids/triglycerides and cholesterol, which showed spatial overlapping with one another and Raman-identified hydroxyapatite. Moreover, the Raman patterns correlated with those displayed by both von-Kossa-calcium- and Nile-blue-stained serial cryosections. Raman analysis also provided the first identification of carotenoids, which co-localized with the identified lipid moieties. Additional fit concerned the distribution of collagen and elastin. The good correlation of Raman maps with high-affinity staining patterns proved that Raman microspectroscopy is a reliable tool in evaluating calcification degree, alteration/displacement of extracellular matrix components, and accumulation rate of different lipid forms in calcified heart valves. In addition, the novel identification of carotenoids supports the concept that valve stenosis is an atherosclerosis-like valve lesion, consistently with their previous Raman microspectroscopical identification inside atherosclerotic plaques.
\end{abstract}

\section{Introduction}

Calcific aortic valve stenosis (CAVS) still represents the leading indication for valve replacement in aging Western populations. CAVS shares clinical and histopathological features with atherosclerosis, ${ }^{1-3}$ leading to the increasingly accepted concept that these two diseases may represent the same disorder occurring in different anatomical sites. ${ }^{4,5}$ Notably, in both stenotic valves ${ }^{2,3}$ and atherosclerotic plaques ${ }^{6,7}$ calcium salt precipitation on accumulated cholesterol has been reported as a distinctive event. What cause-and-effect relationship may exist between the presence of this neutral lipid and calcium salt nucleation is yet to be exhaustively elucidated, in contrast with the more easily conceivable involvement of negatively charged phospholipids (PLs) in pathological biomineralization processes. Consistently, cell-membranederived acidic PLs have been identified as major calcium nucleator in both $\mathrm{CAVS}^{8,9}$ and atherosclerosis. ${ }^{10}$ In addition, using the procalcific subdermal model, PL involvement has been ultrastructurally shown in the context of a peculiar degenerative process affecting aortic valve interstitial cells (AVICs), in which the crucial event was a progressive colliquation of all cell membranes, culminating with the generation of an acidic-PL-rich material outlining dying cells or their remnants and acting as a major hydroxyapatite (HA) nucleator. ${ }^{11-14}$ Similar cell degeneration has also been shown to concern AVICs in in vitro models simulating dystrophic ${ }^{15}$ and metastatic ${ }^{16}$ calcification. Raman microspectroscopy is an analytical technique measuring the characteristic molecular vibrations of various chemical groups after irradiation with a laser beam. ${ }^{17}$ Using this technique, HA, cholesterol, and carotenoids have been identified within atherosclerotic plaques, ${ }^{18-20}$ whereas identification of HA solely has been reported for stenotic aortic valves..$^{21,22}$

The present investigation was aimed to better characterize tissue alterations and parallel accumulation of HA and different lipids in CAVS-affected aortic valve leaflets as well as evaluate whether Raman microspectroscopy can be concerned as a potential diagnostic tool, by matching the achieved ex vivo Raman maps against specific histological patterns. Raman maps of HA, PLs/triglycerides (PLs/TGs), cholesterol, and carotenoids exhibited spatial overlapping with one another and histological patterns, besides providing the novel identification of carotenoids in these calcific valves.
Correspondence: Prof. Fulvia Ortolani, Department of Experimental and Clinical Medicine, University of Udine, Piazzale Kolbe 3, I-33100, Udine, Italy.

Tel. +39.0432 .494242 - Fax: +39.0432 .494201 .

E-mail: fulvia.ortolani@uniud.it

Key words: Valve calcification, stenosis, carotenoids, lipids, Raman microspectroscopy.

Contributions: all authors contributed equally.

Conflict of interest: the authors declare no conflict of interest.

Received for publication: 20 January 2015

Accepted for publication: 5 March 2015.

This work is licensed under a Creative Commons Attribution NonCommercial 3.0 License (CC BYNC 3.0).

(C) Copyright A. Bonetti et al., 2015

Licensee PAGEPress, Italy

European Journal of Histochemistry 2015; 59:2505 doi:10.4081/ejh.2015.2505

\section{Materials and Methods}

\section{Sampling and initial processing}

Native, tricuspid aortic valves were surgically explanted from patients $(n=4$; mean age $78 \pm 8$ years) subjected to cardiac valve replacement at the Cardiothoracic Surgery Unit of the University Hospital of Udine. The present investigation was approved by the Internal Review Board (IRB) of the Department of Experimental and Clinical Medicine so human studies have been performed in accordance with the ethical standards laid down in the 1964 Declaration of Helsinki and its later amendments. Informed consent allowing aortic valve use for experimental purposes was signed by all patients prior to their inclusion in the study. All aortic valves were affected by severe, non-rheumatic stenosis as diagnosed by pre-operative clinical and echocardiographic parameters (valve area $<1 \mathrm{~cm}^{2}$; middle transvalvular gradient $>65 \mathrm{mmHg}$ ). After explantation, aortic valves were immersed in sterile $0.9 \% \mathrm{NaCl}$ solution and their leaflets were excised and subdivided into two hemicusps by cutting them along the middle longitudinal axis. For each patient, one hemi-cusp was cooled by dipping into 2 -methylbutane liquid for subsequent Raman and histological analyses, being the other one formalin-fixed for routinary hematoxylin\&eosin staining. 


\section{Cryosectioning}

For each cooled hemi-cusp, three 1.5-mmspaced, $15-\mu$ m-thick cryosections $(n=12)$ were longitudinally cut, mounted on $\mathrm{CaF}_{2}$ slides, airdried, and stored at $-20^{\circ} \mathrm{C}$ for subsequent Raman microspectroscopic examination. Additional serial and para-serial 8- $\mu$ m-thick cryosections were mounted on glass slides, airdried, and fixed with phosphate-buffered 5\% formaldehyde for subsequent histological staining, as described below.

\section{Raman microspectroscopy}

Raman maps were collected in back scattering geometry using the Renishaw InVia Raman microscope equipped with a $785 \mathrm{~nm}$ diode laser delivering $170 \mathrm{~mW}$ of laser power at the sample. A $785 \mathrm{~nm}$ near infrared wavelength was used to limit tissue autofluorescence, which should interfere with Raman spectrum measurements. The $\mathrm{CaF}_{2}$ slide supporting the tissue sections was mounted on a ProScan II motorized stage (Prior, Cambridge, UK) under the microscope. A Leica 50 microscope objective (N.A. 0.85) focused the laser on the sample. A $1200 \mathrm{~L} / \mathrm{mm}$ grating yielded a spectral resolution of $4 \mathrm{~cm}^{-1}$. A thermoelectrically cooled charge coupled device (CCD) camera was used for detection. The spectrograph was calibrated using the lines of a Ne lamp. Mapping was achieved collecting spectra with steps of $12 \mu \mathrm{m}$, with $10 \mathrm{sec}$ exposure time for each spectrum, for a total of 5708 spectra, each consisting of 1203 data points. Spectra were obtained in the $600-1800 \mathrm{~cm}^{-1}$ region using the synchro mode of the instrument software WiRE ${ }^{\mathrm{TM}} 3.2$ (Renishaw), in which the grating is continuously moved to obtain Raman spectra of extended spectral regions. Data preprocessing and analysis were carried out using the hyperSpec package (Beleites and Sergo, hyperSpec: a package to handle hyperspectral data sets in R; http://hyperspec.r-forge.r-project.org/).

\section{High-affinity histological staining}

\section{von Kossa staining}

Serial cryosections were treated with $1 \%$ silver nitrate solution for $15 \mathrm{~min}$, with exposure to direct sunlight, and 5\% sodium thiosulfate reducing solution for $5 \mathrm{~min}$. Cryosections were then weakly counterstained with hematoxylin and eosin, dehydrated in graded ethanols, cleared with xylene, and mounted with Eukitt ${ }^{\circledR}$ mounting medium.

\section{Movat staining}

Para-serial cryosections were stained with $1 \%$ alcian blue acidic solution for $40 \mathrm{~min}$, differentiated in $0.3 \%$ sodium carbonate solution for $2 \mathrm{~h}$, and then incubated with i) Weigert's resorcin-fuchsin solution for $40 \mathrm{~min}$; ii) celes- tine blue solution for $5 \mathrm{~min}$; iii) Weigert's iron hematoxylin for $10 \mathrm{~min}$; and iv) van Gieson solution for $5 \mathrm{~min}$. Dehydration and mounting were as described above.

\section{Nile blue staining}

Para-serial cryosections were stained with $1 \%$ Nile blue solution at $60^{\circ} \mathrm{C}$ for $5 \mathrm{~min}$, differentiated in warm $1 \%$ acetic acid solution, and mounted with glycerol mounting medium. Discrimination between neutral lipids and acidic lipids is allowed because the used dye is a mixture of oxazone (Nile red) and oxazine sulphate (Nile blue), in that the former is mainly dissolved by neutral lipids and the latter by acidic ones. Observation and recording were made using a Zeiss AxioImager photomicroscope.

\section{Results}

Figure 1 shows the Raman spectrum calculated as the average of all intensity-normalized spectra collected in the map from a representative CAVS-affected valve leaflet cryosection. All the bands usually observed in Raman spectra of biological tissues were detected, such as the sharp and intense band at $1004 \mathrm{~cm}^{-1}$ assigned to the phenylalanine ring vibration, the bands at $1250-1270 \mathrm{~cm}^{-1}$ and $1600-1700 \mathrm{~cm}^{-1}$ assigned to amide I and III vibrational modes respectively, and the bands at $1400-1500 \mathrm{~cm}^{-1}$ assigned to $-\mathrm{CH}_{2-}$ and $-\mathrm{CH}_{3}-$ deformation modes.
Characteristic spectral peaks were also detected of type B carbonate $\mathrm{HA}$ at $959 \mathrm{~cm}^{-1}$, collagen at 877,922 , and $939 \mathrm{~cm}^{-1}$, elastin at 1103 and $1340 \mathrm{~cm}^{-1}$, PLs/TGs at 719 and $1738 \mathrm{~cm}^{-1}$, cholesterol at 700 and $741 \mathrm{~cm}^{-1}$, and carotenoids at 1159 and $1527 \mathrm{~cm}^{-1}$. The presence of unsaturated lipids was inferred from the small, but still distinguishable, peak at $1660 \mathrm{~cm}^{-1}$ superimposing to the broad amide I protein peak. Peaks at 1064 and $1128 \mathrm{~cm}^{-1}$ indicated the presence of saturated fatty acid chains. ${ }^{23}$ All spectra collected from the other cryosections revealed the presence of the same chemical species, although showing slight changes in their peak intensities (not shown).

The measured Raman intensities were further converted into chemical images displaying the relative concentrations of the chemical species identified in the analyzed valve leaflet cross cryosections side-by-side, so including all three layers called tunica fibrosa, tunica spongiosa, and tunica ventricularis, in which major tissue alterations were detectable in the fibrosa layer (Figure $2 \mathrm{~A}-\mathrm{C}$ and G-I). The expression relative concentrations means that in each image color scales span minimum to maximum concentration values of the chemical species in its own map, so they cannot be quantitatively compared to each other. The Raman map of HA (Figure 2A) showed the highest intensity to coincide exactly with the brown calcific nodule recognizable on the serial cryosection subjected to von Kossa silver staining (Figure 2D). Lower HA intensity resulted for two pseudo-triangle-shaped areas

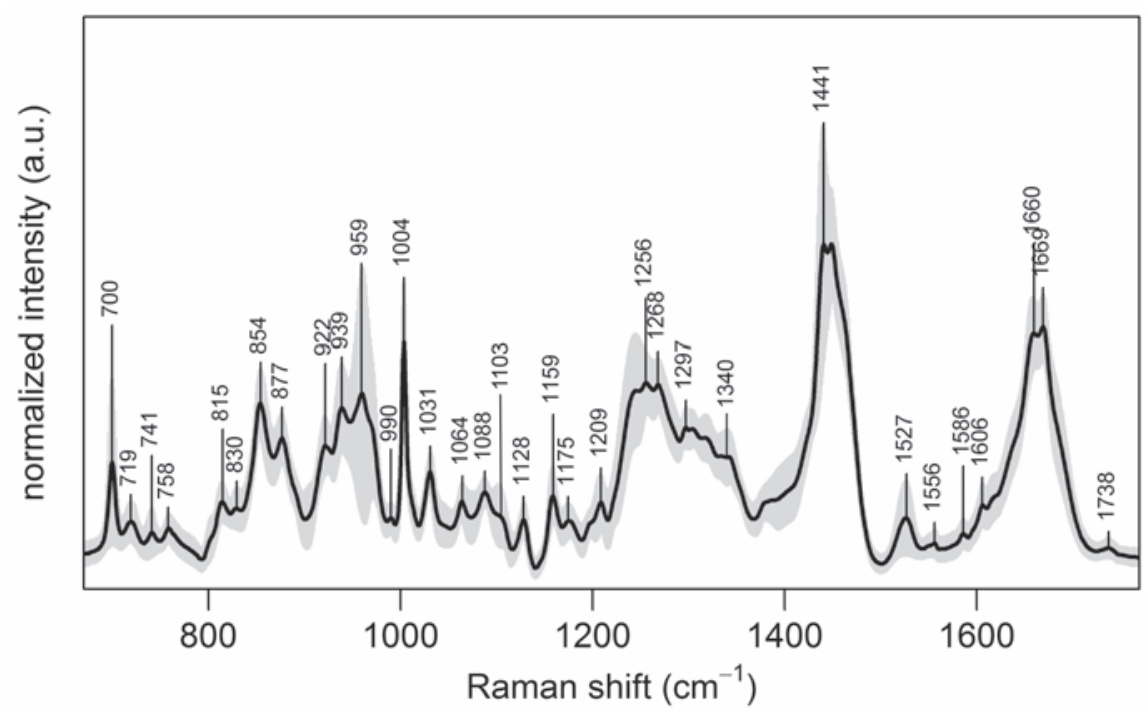

Figure 1. Mean Raman spectrum of the Raman map collected from a representative CAVS-affected valve leaflet cryosection, calculated over all the 5708 spectra of the map. Intensity standard deviation, showing the spectral variability, is shown in light grey. For all spectra, excitation wavelength was at $785 \mathrm{~nm}$, laser power was $170 \mathrm{~mW}$, and acquisition time was 10 seconds. 
in the fibrosa layer referred to below as T1 and $\mathrm{T} 2$, the former enveloping the calcific nodule and the latter located above. Additional very high intensity was exhibited by random onepixel-wide spots located in T1. Also these spots roughly correlated with the punctate silver precipitates showed by the von-Kossa-stained cryosection inside the corresponding area. In contrast, the HA Raman map showed a mutual exclusion pattern as opposed to those of collagen (Figure 2B) and elastin (Figure 2C), since the areas showing higher mineral intensity were superimposable to those of lower intensity of the two extracellular matrix fibrous components. In turn, Raman patterns of the latter were roughly consistent with their distribution on histological cryosections, revealing both fibrous components by eosin on the counterstained von-Kossa-reacted cryosection (Figure 2D) as well as collagen in red and elastin in dark brown on the Movat-stained cryosection (Figure 2E). Further fitting resulted for the maps of the three lipid moieties identified, which were closely superimposable to each other (Figure 2 G-I). In addition, the areas showing intermediate intensity of PLs/TGs (Figure 2G), cholesterol (Figure 2H), and carotenoids (Figure 2I) correlated with both T1 and $\mathrm{T} 2$ areas in the HA map, including the presence of single or clustered one-pixel-wide spots with high intensity. Surprisingly, there was the exception that lipid maps showed minimal intensity just in the area exhibiting the highest intensity in the HA map, i.e. the calcific nodule, although some intranodular intensity appeared for PLs/TGs. Raman maps of lipids were also roughly consistent with the histological patterns shown by the cryosection subjected to Nile blue lipid staining (Figure 2F), since a red-stained triangle-shaped area, indicating the presence of neutral lipids, corresponded to T1 on lipid Raman maps and single or clustered blue-stained punctate sites, indicating the presence of acidic lipids, were scattered inside this T1-like area correlating with topical high Raman intensity of PLs/TGs. In contrast, a T2-like area was not shown by the histological counterpart. On the other hand, prominent Nile blue staining was apparent at the calcific nodule edge, preserved from artifactual detachment. All Raman maps concerning the other cryosections were consistent with the histological counterparts, although they showed different topographical distributions of the identified chemical species (not shown).

\section{Discussion}

The present investigation showed that good consistency exists between Raman maps and specific histological patterns derived from cryosections of CAVS-affected valve leaflets, leading to conclude that this vibrational microspectroscopy represents a reliable technique to identify unknown chemical species or validate those revealed by high-affinity histological procedures. Combining these two approaches, the identification, typization, and localization of HA and distinct lipid forms were the major outcomes. In particular, HA Raman maps showed the highest mineral intensity to correspond exactly to calcific nodules on the histological counterpart. As inferred from the Raman shift of the $v_{1} \mathrm{PO}_{4}^{3-}$ band at $959 \mathrm{~cm}^{-1}$, the precipitated mineral was type $\mathrm{B}$ carbonate $\mathrm{HA},{ }^{24}$ as recently reported using the same technique. ${ }^{21,22}$ Taking into account that type $B$ carbonate HA represents the most abundant form of bioapatite in young bones, ${ }^{25}$ the present
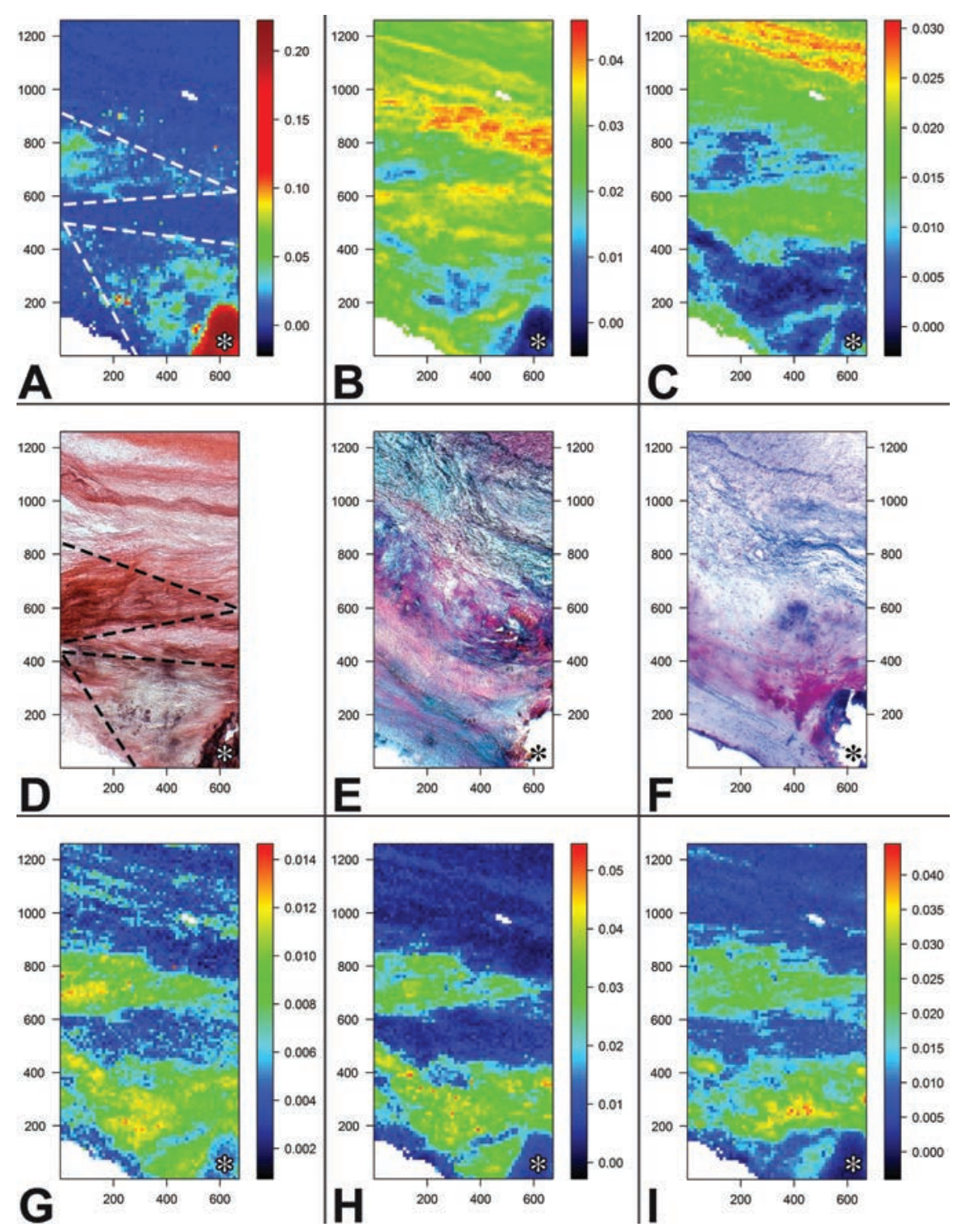

Figure 2. Images obtained from the Raman map showing the total normalized intensity of A) hydroxyapatite peak $\left(959 \mathrm{~cm}^{-1}\right)$; B) collagen peaks $\left(877,922\right.$, and $\left.939 \mathrm{~cm}^{-1}\right)$; C) elastin peaks (1103 and $\left.1340 \mathrm{~cm}^{-1}\right)$; G) phospholipid/triglyceride peaks (719 and 1738 $\left.\left.\mathrm{cm}^{-1}\right) ; \mathrm{H}\right)$ cholesterol peaks (700 and $\left.741 \mathrm{~cm}^{-1}\right)$; I) carotenoid peaks (1159 and 1527 $\left.\mathbf{c m}^{-1}\right)$. Color scale bars refer to arbitrary units of total normalized intensities. Histological pictures obtained from D) a serial cryosection subjected to von Kossa calcium staining and para-serial cryosections stained with E) Movat pentachrome method for extracellular matrix components or F) Nile blue method for neutral and acidic lipids. Two triangleshaped regions are outlined (dashed lines in A and D) in which correlating features can be appreciated; these regions are promptly recognizable in all Raman images (A-C and G-I) and are referred as T1 and T2 regions in the text. A calcific nodule portion (asterisk) is displayed in the lower right corner. Histological slide original magnification: $5 x$. Abscissa and ordinate values are expressed in $\mu \mathrm{m}$. 
result might be consistent with heterotopic ossification taking place in CAVS. However, it should be emphasized that i) bone-formed territories were never histologically encountered in this investigation; and ii) bone metaplasia was reported to be associated with dystrophic calcification in less than $13 \%$ of hundreds of aortic valves and dozens of mitral valves. ${ }^{26,27}$ Such a specification is needed because valve calcification is often misconceived as valve ossification instead of considering this latter as an alternative, minority pro-calcific event.

Besides showing marked co-localization of the three moieties identified, Raman maps of lipids were also found to be consistent with lipid distribution in the histological counterpart. Major fitting concerned the good superimposability of T1 in the cholesterol Raman map with the neutral-lipid-rich red area in the Nile-blue-stained cryosection. In the latter, some parallelism between the distribution of acidic-lipid-rich blue punctate sites and that of very intense one-pixel-wide spots inside $\mathrm{T} 1$ in the PL/TG Raman map resulted as well. However, there were also some inconsistencies, the most apparent being the lack of a T2like area in the histological counterpart. It should be kept in mind that uncontrollable events can affect reliability and reproducibility of the patters supplied by this high-affinity staining, depending on heterogeneous dye-tosubstratum affinities and not steady stain-tostain competition degrees. The existence of further consistency between the lipid Raman maps and that of HA supports the finding that lipid accumulation closely correlates with priming of biomineralization, in spite of the prima facie contradictory very low lipid intensity just at level of the calcific nodule. Likely, this conflicting result can be ascribed to a masking effect exerted by the overwhelming precipitation of HA crystals at the level of this prominently calcified area. Taking into account that i) PLs/TGs were the sole lipid moiety showing some intensity inside the calcific nodule area; and ii) prominent Nile blue staining was apparent at calcific nodule edges, the concept supported is that a major role in HA crystal precipitation is played by PLs, consistent with reports on ectopic calcification including in vivo pathological conditions ${ }^{8,9}$ as well as experimental ones using in vivo ${ }^{11-14}$ and in vitro ${ }^{15,16}$ models. The microspectroscopic identification of cholesterol in mineralizing areas is consistent with neutral lipid accumulation representing a distinctive feature of $\mathrm{CAVS},{ }^{2,3}$ in which oxidized cholesterol might contribute to valve mineralization. ${ }^{28}$

To our knowledge, this study provided the first-time identification of carotenoids in stenotic valve leaflets, besides revealing their co-accumulation with the other lipid forms at valve mineralizing areas. Being carotenoids transported in the human plasma by LDLs together with cholesterol, ${ }^{29}$ it might be assumed that LDL-cholesterol-carotenoid complexes are phagocytized by lipid-loading macrophages and AVICs during the early stages of CAVS. Since Raman microspectroscopy already revealed the presence of carotenoids as well as their co-localization with lipid deposits in atherosclerotic plaques, ${ }^{18-20}$ the concept is supported that CAVS represents a type of valve atherosclerosis, 4,5 with progressive LDL entering and lipid-laden cell degeneration/death being shared features in these two types of cardiovascular diseases. Taking also into account that i) carotenoids can be revealed very easily because of their very intense spectral peaks, and ii) Raman spectra were already obtained in vivo by shining the laser beam upon artery wall atherosclerotic lesions via miniaturized fiber-optical probes, ${ }^{30,31}$ it is worth noting that the in vivo microspectroscopic identification of carotenoids might be usefully exploited to improve the poor capability of a precocious CAVS diagnosis.

Good consistency between Raman maps and histological patterns resulted also for collagen distribution, since mapped areas showing very low collagen intensity roughly corresponded to those completely lacking in eosinophilia in the histological counterpart. Since the same areas in turn roughly corresponded to those with very high HA intensity, it is feasible that in valve mineralizing areas degeneration of collagen fibers may take place, consistent with inflammation-dependent release of matrix metalloproteinases by resident AVICs. $^{3}$ Additional consistency concerned elastin distribution since both the Raman map and the Movat-stained para-serial cryosection showed this protein to be mainly present in the ventricularis layer, consistent with native valve leaflet structure as well as the fact that this valve region usually retains its normal features remaining free from mineralization. ${ }^{2}$

In conclusion, Raman maps added information on the presence and topographical distribution of precipitated calcium, accumulated lipids including cholesterol/carotenoids, and altered extracellular matrix components in CAVS-affected valve leaflets. Moreover, Raman microspectroscopy was found to represent a potential technique to investigate in vivo the alterations anticipating or characterizing this atherosclerosis-like valve disease.

\section{References}

1. Stewart BF, Siscovick D, Lind BK, Gardin JM, Gottdiener JS, Smith, et al. Clinical factors associated with calcific aortic valve disease. Cardiovascular Health Study. J Am Coll Cardiol 1997;29:630-4.

2. Otto CM, Kuusisto J, Reichenbach DD, Gown AM, O'Brien KD. Characterization of the early lesion of "degenerative" valvular aortic stenosis. Histological and immunohistochemical studies. Circulation 1994; 90:844-53.

3. 0'Brien KD, Reichenbach DD, Marcovina SM, Kuusisto J, Alpers CE, Otto CM. Apolipoproteins B, (a), and E accumulate in the morphologically early lesion of "degenerative" valvular aortic stenosis. Arterioscler Thromb Vasc Biol 1996; 16:523-32.

4. Agmon Y, Khandheria BK, Miessner I, Sicks JR, O'Fallon WM, Wiebers D0, et al. Aortic valve sclerosis and aortic atherosclerosis: different manifestations of the same disease? Insights from a populationbased study. J Am Coll Cardiol 2001; 38:827-34.

5. Kuusisto J, Räsänen K, Särkioja T, Alarakkola E, Kosma VM. Atherosclerosislike lesions of the aortic valve are common in adults of all ages: a necropsy study. Heart 2005;91:576-82.

6. Hirsch D, Azoury R, Sarig S, Kruth HS. Colocalization of cholesterol and hydroxyapatite in human atherosclerotic lesions. Calcif Tissue Int 1993;52:94-8.

7. Sarig, S, Weiss TA, Katz I, Kahana F, Azoury R, Okon E, et al. Detection of cholesterol associated with calcium mineral using confocal fluorescence microscopy. Lab Invest 1994;71:782-87.

8. Kim KM, Trump BF. Amorphous calcium precipitates in human aortic valve. Calcif Tiss Res 1975;18:155-60.

9. Kim KM. Calcification of matrix vesicles in human aortic valve and aortic media. Fed Proc 1976;35:156-62.

10. Dmitrovsky E, Boskey AL. Calcium-acidic phospholipid-phosphate complexes in human atherosclerotic aortas. Calcif Tissue Int 1985;37:121-25.

11. Ortolani F, Petrelli L, Tubaro F, Spina M, Marchini M. Novel ultrastructural features as revealed by phthalocyanine reactions indicate cell priming for calcification in subdermally implanted aortic valves. Connect Tissue Res 2002;43:44-55.

12. Ortolani F, Tubaro F, Petrelli L, Gandaglia A, Spina M, Marchini M. Copper retention, calcium release and ultrastructural evidence indicate specific Cuprolinic Blue uptake and peculiar modifications in mineralizing aortic valves. Histochem J 2002b;34:41-50.

13. Ortolani F, Petrelli L, Nori SL, Gerosa G, Spina M, Marchini M. Malachite green and phthalocyanine-silver reactions reveal acidic phospholipid involvement in calcifi- 
cation of porcine aortic valves in rat subdermal model. Histol Histopathol 2003;18:1131-40.

14. Ortolani F, Bonetti A, Tubaro F, Petrelli L, Contin M, Nori SL, et al. Ultrastructural characterization of calcification onset and progression in subdermally implanted aortic valves. Histochemical and spectrometric data. Histol Histopathol 2007;22:261-72.

15. Ortolani F, Rigonat L, Bonetti A, Contin M, Tubaro F, Rattazzi M, et al. Pro-calcific responses by aortic valve interstitial cells in a novel in vitro model simulating dystrophic calcification. Ital $\mathbf{J}$ Anat Embryol 2010;115:135-39.

16. Bonetti A, Della Mora A, Contin M, Tubaro F, Marchini M, Ortolani, F. Ultrastructural and spectrophotometric study on the effects of putative triggers on aortic valve interstitial cells in in vitro models simulating metastatic calcification. Anat Rec 2012;295:1117-27.

17. Smith WE, Dent G. Modern Raman spectroscopy: a practical approach. Wiley, Chichester, 2005.

18. Römer TJ, Brennan JF 3rd, Fitzmaurice M, Feldstein ML, Deinum G, Myles JL, et al. Histopathology of human coronary atherosclerosis by quantifying its chemical composition with Raman spectroscopy. Circulation 1998;97:878-85.

19. Buschman HP, Motz JT, Deinum G, Römer TJ, Fitzmaurice M, Kramer JR, et al. Diagnosis of human coronary atheroscle- rosis by morphology-based Raman spectroscopy. Cardiovasc Pathol 2001;10:59-68.

20. van de Poll SW, Kastelijn K, Bakker Schut TC, Strijder C, Pasterkamp G, Puppels GJ, et al. On-line detection of cholesterol and calcification by catheter based Raman spectroscopy in human atherosclerotic plaque ex vivo. Heart 2003;89:1078-82.

21. Mangialardo S, Cottinogli V, Cavaretta E, Salvador L, Postorino P, Maras A. Pathological biominerals: Raman and infrared studies of bioapatite deposits in human heart valves. Appl Spectrosc 2012; 66:1121-27.

22. Pilarczyk M, Czamara K, Baranska M, Natorska J, Kapusta P, Undas A, et al. Calcification of aortic human valves studied in situ by Raman microimaging: following mineralization from small grains to big deposits. J Raman Spectrosc 2013; 44:1222-29.

23. DeGelder J, De Gussem K, Vandenabeele P, Moens L. Reference database of Raman spectra of biological molecules. J Raman Spectrosc 2007;38:1133-47.

24. Penel G, Leroy G, Rey C, Bres E. MicroRaman spectral study of the P04 and C03 vibrational modes in synthetic and biological apatites. Calfic Tissue Int 1998; 63:475-81.

25. Rey C, Collins B, Goehl T, Dickson IR, Glimcher M. The carbonate environment in bone mineral: a resolution-enhanced Fourier transform spectroscopy study.
Calcif Tissue Int 1989;45:157-64.

26. Mohler ER 3rd, Gannon F, Reynolds C, Zimmerman R, Keane MG, Kaplan FS. Bone formation and inflammation in cardiac valves. Circulation 2001;103:1522-28.

27. Steiner I, Kasparová P, Kohout A, Dominik J. Bone formation in cardiac valves: a histopathological study of 128 cases. Virchows Arch 2007;450:653-57.

28. Olsson M, Thyberg J, Nilsson J. Presence of oxidized low density lipoprotein in nonrheumatic stenotic aortic valves. Arterioscler Thromb Vasc Biol 1999;19: 1218-22.

29. Parker RS. Absorption, metabolism, and transport of carotenoids. FASEB J 1996;10:542-51.

30. Buschman HP, Marple ET, Wach ML, Bennett B, Schut TC, Bruining HA, et al. In vivo determination of the molecular composition of artery wall by intravascular Raman spectroscopy. Anal Chem 2000;72: 3771-75.

31. Motz JT, Fitzmaurice M, Miller A, Gandhi SJ, Haka AS, Galindo LH, et al. In vivo Raman spectral pathology of human atherosclerosis and vulnerable plaque. J Biomed Opt 2006;11:021003.

32. Kaden JJ, Dempfle CE, Grobholz R, Tran HT, Kiliç R, Sarikoç A, et al. Interleukin-1 beta promotes matrix metalloproteinase expression and cell proliferation in calcific aortic valve stenosis. Atherosclerosis 2003;170:205-11. 


\section{Apigenin induces dermal collagen synthesis via smad $2 / 3$ signaling pathway}

\author{
Y. Zhang, ${ }^{1}$ J. Wang, ${ }^{1}$ X. Cheng, ${ }^{2}$ B. Yi, ${ }^{3}$ \\ X. Zhang, ${ }^{4}$ Q. Li $^{1}$ \\ 'Department of Plastic and \\ Reconstructive Surgery, Shanghai $9^{\text {th }}$ \\ People's Hospital, School of Medicine, \\ Shanghai Jiao Tong University \\ 2Department of Urology, Renji Hospital, \\ School of Medicine, Shanghai Jiao Tong \\ University \\ ${ }^{3}$ Clinical College of General Hospital of \\ Beijing Military Region, Anhui Medical \\ University, Hefei \\ ${ }^{4}$ The Key Laboratory of Stem Cell \\ Biology, Institute of Health Sciences, \\ Shanghai Institutes for Biological \\ Sciences, Chinese Academy of Sciences \\ and Shanghai Jiao Tong University School \\ of Medicine, Shanghai, China
}

\section{Abstract}

Decrease in fibroblast-produced collagen has been proven to be the pivotal cause of skin aging, but there is no satisfactory drug which directly increases dermal thickness and collage density. Here we found that a flavonoid natural product, apigenin, could significantly increase collagen synthesis. NIH/3T3 and primary human dermal fibroblasts (HDFs) were incubated with various concentrations of apigenin, with dimethyl sulfoxide (DMSO) serving as the negative control. Real-time reversetranscription polymerase chain reaction (PCR), Western Blot, and Toluidine blue staining demonstrated that apigenin stimulated type-I and type-III collagen synthesis of fibroblasts on the mRNA and protein levels. Meanwhile, apigenin did not induce expression of alpha smooth muscle actin ( $\alpha$-SMA) in vitro and in vivo, a fibrotic marker in living tissues. Then the production of collagen was confirmed by Masson's trichrome stain, Picrosirius red stain and immunohistochemistry in mouse models. We also clarified that this compound induced collagen synthesis by activating smad2/3 signaling pathway. Taken together, without obvious influence on fibroblasts' apoptosis and viability, apigenin could promote the type-I and type-III collagen synthesis of dermal fibroblasts in vitro and in vivo, thus suggesting that apigenin may serve as a potential agent for esthetic and reconstructive skin rejuvenation.

\section{Introduction}

Dermis consists of several structural components, and collagen takes the major part. In addition to glycosaminoglycans and elastin fibers, dermal matrix in adult skin are composed of type I (80-85\%) and type III collagen $(10-15 \%) .{ }^{1}$ It is of great importance that collagen plays a main role in the texture and appearance of skin. Skin aging is inevitably associated with a disturbance in collagen metabolism $^{2}$ (due to the decreased activity of fibroblasts and their collagen synthesis), as well as elastin. Increasing the collagen content of dermis has been regarded as a well-effective way for anti-aging in skin.

Collagen is a kind of biomacromolecule and it cannot be absorbed through the stratum corneum. Recently, some researches demonstrated that collagen hydrolysate ingestion might be beneficial to slow chronological skin aging $^{3}$ and photoaging ${ }^{4}$ in rats, and the density of collagen fibrils increased compared with lactalbumin and water controls. ${ }^{5}$ But the clinical effect of oral collagen hydrolysate still lacks convincing evidences. Up to now, injectable collagen $^{1}$ or analogous composition ${ }^{6}$ filling implants are recognized as the well-accepted treatment modality for cosmetic purposes. However, maintaining skin appearance relies on expansive and complex treatment repeatedly because of the short-term duration of exogenic injected collagen.

Apigenin (4,5,7-trihydroxyflavone), a flavone subclass of flavonoid widely distributed in many herbs, fruits, and vegetables, is a substantial component of the human diet and has been shown to possess a variety of biological characteristics, including anti-oxidative, ${ }^{7}$ antiinflammatory effect, ${ }^{8}$ tumor growth inhibition ${ }^{9}$ and promoting neurogenesis. ${ }^{10}$ It has been shown that apigenin could enhance wound healing and tissue repair in diabetic rat skin. ${ }^{11}$ In the process of wound healing, fibroblasts secreted collagen and the formation of collagen-rich granulation tissue are vital pathophysiological mechanisms for wound closure. ${ }^{12}$

Given this, we wonder what effect would apigenin have on fibroblasts and whether apigenin could induce collagen synthesis in normal human dermal fibroblasts. Consequently, we examined its effects on collagen synthesis in normal human dermal fibroblasts in vitro and tested its function in the skin aging mouse model induced by D-Galactose. Furthermore, we investigated the potential mechanism involved in the positive effects of apigenin on collagen expression in fibroblasts.
Correspondence: Xiaoling Zhang and Qingfeng $\mathrm{Li}$, Department of Plastic and Reconstructive Surgery, Shanghai $9^{\text {th }}$ People's Hospital, Shanghai Jiao Tong University School of Medicine, 639 Zhizaoju Road, Shanghai 200011, China.

Tel. +86.21.23271699-5615 - Fax: +86.21.63089567. E-mails: (X. Zhang) xlzhang@sibs.ac.cn; (Q. Li) dr.liqingfeng@yahoo.com

Key words: Apigenin, flavonoid, collagen I/II, fibroblasts, smad2/3.

Contributions: YZ and JW contributed equally to this work; YZ, JW, experimental work, data collection and interpretation; $\mathrm{XC}$, participation in experimental work design and coordination, data acquisition; BY, participation in study design, data collection, analysis of data and manuscript preparation; QL, XZ, study design, data analysis and interpretation, manuscript drafting.

Conflict of interest: the authors declare no conflict of interest.

Funding: this study was supported by grants from the key project of the National Natural Science Foundation (No. 81230042), the National Key Project of Scientific and Technical Supporting Programs Funded by Ministry of Science \& Technology of China (No. 2012BAI11B03) (Q. Li) and the Chinese Academy of Sciences (No. XDA01030102), Shanghai Municipal Commission of Health and Family Planning (No. 2013ZYJB0501) (X. Zhang).

Received for publication: 28 November 2014 . Accepted for publication: 9 March 2015.

This work is licensed under a Creative Commons Attribution NonCommercial 3.0 License (CC BYNC 3.0).

(C) Copyright $Y$. Zhang et al., 2015

Licensee PAGEPress, Italy

European Journal of Histochemistry 2015; 59:2467 doi:10.4081/ejh.2015.2467

\section{Materials and Methods}

\section{Cell culture}

Primary human dermal fibroblasts were obtained from adolescent foreskin tissue of ten people (aged 8-12 years), and none of them had a history with skin diseases. Skin tissue was obtained after obtaining informed consent from the patients, with the approval of the ethics committee of Shanghai $9^{\text {th }}$ People's Hospital and in conformity with the Helsinki guidelines. NIH/3T3 and human dermal fibroblasts (HDFs) were maintained in DMEM (Hyclone, Thermo Fisher Scientific, Waltham, MA, USA) supplemented with $10 \%$ fetal bovine 
serum (Hyclone, Thermo Fisher Scientific), $100 \mathrm{U} / \mathrm{mL}$ penicillin, and $100 \mathrm{mg} / \mathrm{L}$ streptomycin. Both HDFs and NIH/3T3 were incubated at $37^{\circ} \mathrm{C}$ in a humidified atmosphere with $5 \%$ $\mathrm{CO}_{2}$. Primary fibroblasts of passages 6-8 were used. Toluidine blue (Sigma-Aldrich, St. Louis, M0, USA) staining was used to assess extracellular matrix synthesis. ${ }^{13}$

\section{Real-time PCR analysis}

The total RNA of cells was isolated using TRIzol reagent (Invitrogen, Carlsbad, CA, USA) and subjected to reverse transcription with Oligo (dT) and M-MLV Reverse Transcriptase (Thermo Fisher Scientific). Synthesized complementary DNA (cDNA) was analysed with quantitative real-time PCR using SYBR® Premix (Takara, Dalian, China) and Roche480 system. Glyceraldehyde 3-phospate dehydrogenase (GAPDH) was used as a reference gene. Primers sequences were as follows: collagen, type I, alpha 2 (Colla2; mouse), 5 -GGTGAGCCTGGTCAAACGG-3 (forward) and 5 - ACTGTGTCCTTTCACGCCTTT-3 (reverse); Colla2 (human), 5 -GGCCCTCAAGGTTTCCAAGG-3 (forward) and 5-CACCCTGTGGTCCAACAACTC-3 (reverse); collagen, type III, alpha 1 (Col3al; mouse), 5 - CTGTAACATGGAAACTGGGGAAA-3 (forward) and 5 CCATAGCTGAACTGAAAACCACC-3 (reverse); Col3al (human), 5 -TTGAAGGAGGATGTTCCCATCT-3 (forward) and 5- ACAGACACATATTTGGCATGGTT-3 (reverse); matrix metalloproteinases 1 (MMP1; human), 5 AAAATTACACGCCAGATTTGCC-3 (forward) and 5 -GGTGTGACATTACTCCAGAGTTG-3 (reverse); matrix metalloproteinases 2 (MMP2; human), 5 -TACAGGATCATTGGCTACACACC-3 (forward) and 5-GGTCACATCGCTCCAGACT-3 (reverse); matrix metalloproteinases 9 (MMP9; human), 5 -TGTACCGCTATGGTTACACTCG-3 (forward) and 5 GGCAGGGACAGTTGCTTCT-3 (reverse); tissue inhibitor of metalloproteinases1 (TIMP1; human), 5 -CTTCTGCAATTCCGACCTCGT-3 (forward) and 5-ACGCTGGTATAAGGTGGTCTG-3 (reverse); $\alpha$-SMA (human), 5 AAAAGACAGCTACGTGGGTGA-3 (forward) and 5 -GCCATGTTCTATCGGGTACTTC-3 (reverse).

\section{Cell viability assay}

For the cell viability assay, HDFs were seeded on 96-well plates (100 mL per well), followed by apigenin (cat. no. 42251; SigmaAldrich) or DMSO (Sigma-Aldrich) treatment. After 3 or 5 days, cell culture medium was replaced by Thiazolyl Blue Tetrazolium Bromide (MTT) working solution, followed by a 4-hour incubation at $37^{\circ} \mathrm{C}$ in a $5 \% \mathrm{CO}_{2}$ incubator. After MTT working solution was removed and DMSO added, the absorbances at $490 \mathrm{~nm}$ were detected.

\section{Flow cytometric analysis}

Cell apoptosis was assessed by flow cytometry using the Alexa Fluor ${ }^{\circledR} 488$ Annexin V/Dead Cell Apoptosis Kit (Invitrogen, Carlsbad, CA, USA). Following apigenin (5 $\mu \mathrm{mol} / \mathrm{L}$ or 1 $\mu \mathrm{mol} / \mathrm{L}$ ) or dimethyl sulfoxide (DMSO) treatment, harvested cells were suspended in 100 $\mu \mathrm{L}$ Annexin-binding buffer. Then, $5 \mu \mathrm{L}$ Alexa Fluor® 488 Annexin V and $1 \mu \mathrm{L}$ PI working solution were added and incubated with the cells for 15 min in the dark. After the incubation period, $400 \mu \mathrm{L} 1 \mathrm{X}$ Annexin-binding buffer was added and mixed gently. The stained cells were analysed directly by flow cytometry using the Cell Quest program (Becton Dickinson, CA, USA). Data were analysed using FlowJo software.

\section{Colony formation assay}

Anchorage-dependent growth of HDFs were investigated by monolayer colony formation assay. ${ }^{14}$ Cells were cultured in a 6 -well plate (500 per well) and treated with $5 \mu \mathrm{mol} / \mathrm{L}$ or 1 $\mu \mathrm{mol} / \mathrm{L}$ apigenin or DMSO. After cultured for 14 days, surviving colonies were stained $5 \mathrm{~min}$ with Gentian Violet (Sigma-Aldrich) after 4\% paraformaldehyde fixation.

\section{Immunofluorescence cell staining}

Human dermal fibroblasts at a density of $2 \times 10^{3}$ cells per well were seeded on cover slides in 24-well plates and incubated overnight. Cells were fixed with $4 \%$ paraformaldehyde and blocked with $5 \%$ goat serum in PBST $(0.1 \%$ TritonX-100 in phosphate buffered saline) for $1 \mathrm{~h}$. For F-actin staining, cells were incubated with Alexa Fluor 488 Phalloidin (Cytoskeleton Inc., Denver, C0, USA; 1:200) for $1 \mathrm{~h}$ at room temperature. For $\alpha$-SMA staining, cells were incubated with primary antibodies against $\alpha$-SMA (Abcam, Cambridge, UK, 1:200) for $2 \mathrm{~h}$ at room temperature, followed by an Alexa Fluor 555-conjugated secondary antibody. For smad3 staining, cells were incubated with primary antibodies against smad3 (Cell Signaling Technology, Beverly, MA, USA; 1:200) for $2 \mathrm{~h}$ at room temperature, followed by an Alexa Fluor 488-conjugated secondary antibody. Immunofluorescence signals were captured using confocal microscopy (LSM 510, META Laser Scanning Microscope; Zeiss, Jena, Germany).

\section{Smad2/3 knockdown by siRNA}

RNA interference was performed using smad2/3 siRNA (human) (sc-37238; Santa Cruz Biotechnology, Dallas, TX, USA), targeting human smad2/3 and control siRNA (sc37007) as negative control. Transfection for HDFs was conducted using Lipofectamine RNAiMAX reagent (Invitrogen, Carlsbad, CA, USA) according to the manufacturer's protocol.

\section{Western blot}

Cultured cells were lysed using radioimmunoprecipitation assay (RIPA) lysis buffer. Protein concentrations were determined using a micro bicinchoninic acid (BCA) assay (Thermo Fisher Scientific). Twenty micrograms total protein extract was separated by $8 \%$ or $10 \%$ sodium dodecyl sulfate-polyacrylamide gel electrophoresis (SDS-PAGE) under reducing conditions and electroblotted onto polyvinylidene difluoride membranes (Millipore, Bedford, MA, USA). The membrane was then blocked and then incubated with primary antibodies overnight at $4{ }^{\circ} \mathrm{C}$.

The primary antibodies used included the followings: anti-Colla2, anti-Col3a1, anti- $\alpha$ SMA (Abcam; 1:1000), anti-cyclin-dependent kinase (CDK) family, anti-cyclin D1, anticyclin E1, anti-smads, anti-MAPK family (Cell Signaling Technology, Beverly, MA, 1:1000), anti-GAPDH (Sigma-Aldrich; 1:10,000). Immunoreactive bands were quantitatively analyzed with ImageJ software.

\section{D-galactose-induced skin aging mouse model and animal experiments}

Six-week-old female C57BL/6 mice were purchased from the Shanghai Slac Laboratory Animal (Slac, Shanghai, China). All animal studies have been approved by the Animal Care and Use Committee of Shanghai Jiao Tong University. All efforts were made to minimize animal suffering.

A total of 18 mice were randomly assigned to three groups $(n=6)$. Two groups of animals received daily subcutaneous injection of Dgalactose (D-gal; $1000 \mathrm{mg} / \mathrm{kg}$ ) for 8 weeks. ${ }^{15}$ The third group received phosphate buffered saline (PBS) as a negative control. Two weeks later, DMSO and apigenin (5 $\mu \mathrm{mol} / \mathrm{L})$ was delivered by microneedles ${ }^{16}$ [MTS-Roller Model: CR2 $(0.2 \mathrm{~mm})]$ to the dermis of Dgalactose treated mice once a day for 4 weeks, respectively. Mice were sacrificed at the end of treatment, and skin tissue was harvested for further analyses.

\section{Histology and immunohistochemistry}

Paraformaldehyde-fixed paraffin-embedded tissue sections $(5 \mu \mathrm{m})$ were stained with hematoxylin and eosin (H\&E), Masson's trichrome (Trichrome stain LG solution, HT10316; Sigma-Aldrich) and Picrosirius red (Fluka, Buchs, Switzerland). For immunohistochemical staining, the sections were detected with primary antibodies against collagen I/II (Millipore; 1:1,000) and $\alpha$-SMA (Abcam; 1:200) overnight at $4^{\circ} \mathrm{C}$. After incubation with the appropriate secondary antibodies, the sections were developed with diaminobenzidine and counterstained with hematoxylin. 


\section{Statistical analysis}

Statistical differences were calculated using Friedman's analysis of variance (ANOVA), with post-hoc least significant difference (LSD) test as appropriate. A significant difference among groups was set at $\mathrm{P}<0.05$.

A<smiles>O=c1cc(-c2ccc(O)cc2)oc2cc(O)cc(O)c12</smiles>

B

\section{Results}

\section{Apigenin stimulated collagen} synthesis but had no effect on matrix metalloproteinases in vitro

Fibroblasts are the predominant mesenchy- mal cells in the dermis, and their function is strongly implicated in dermatology. To study apigenin's effect on fibroblasts (Figure 1A), NIH/3T3 and HDFs were administered with apigenin at the concentrations of $5 \mu \mathrm{mol} / \mathrm{L}$. As shown in Figure 1B, apigenin could potently increase Toluidine blue staining after apigenin treatment for 5 days, which mean the
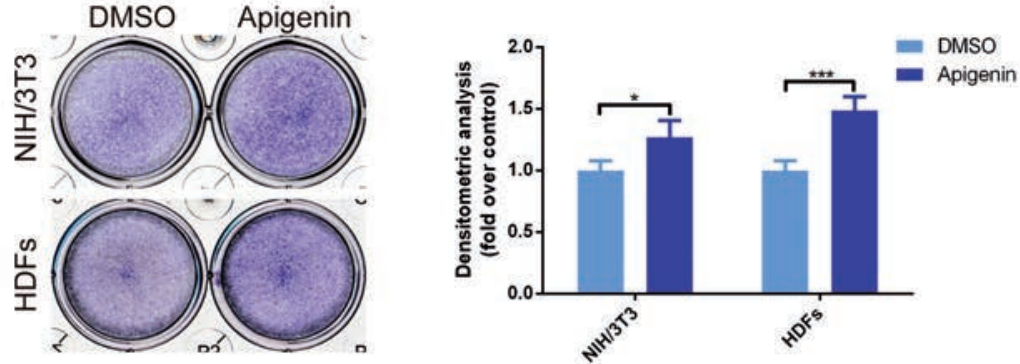

C
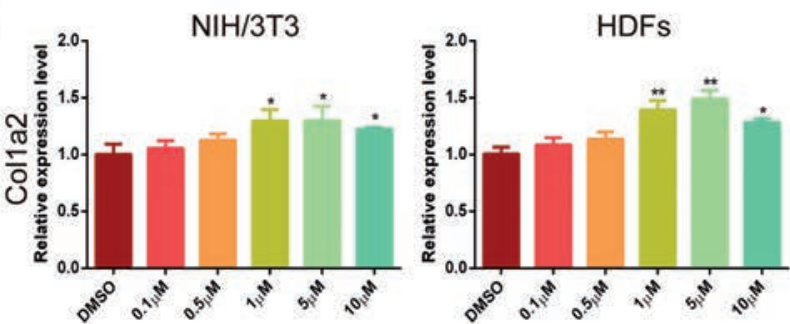

D
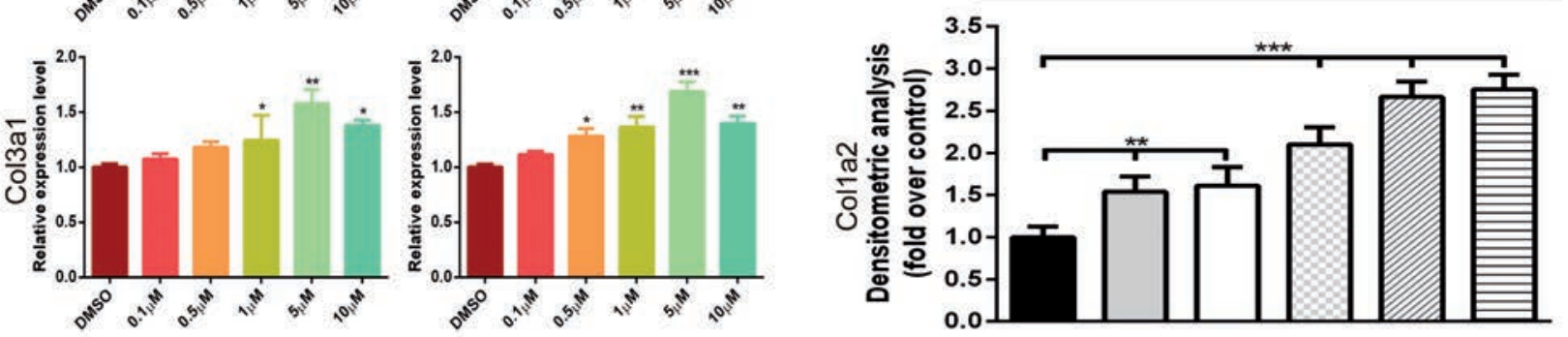

E
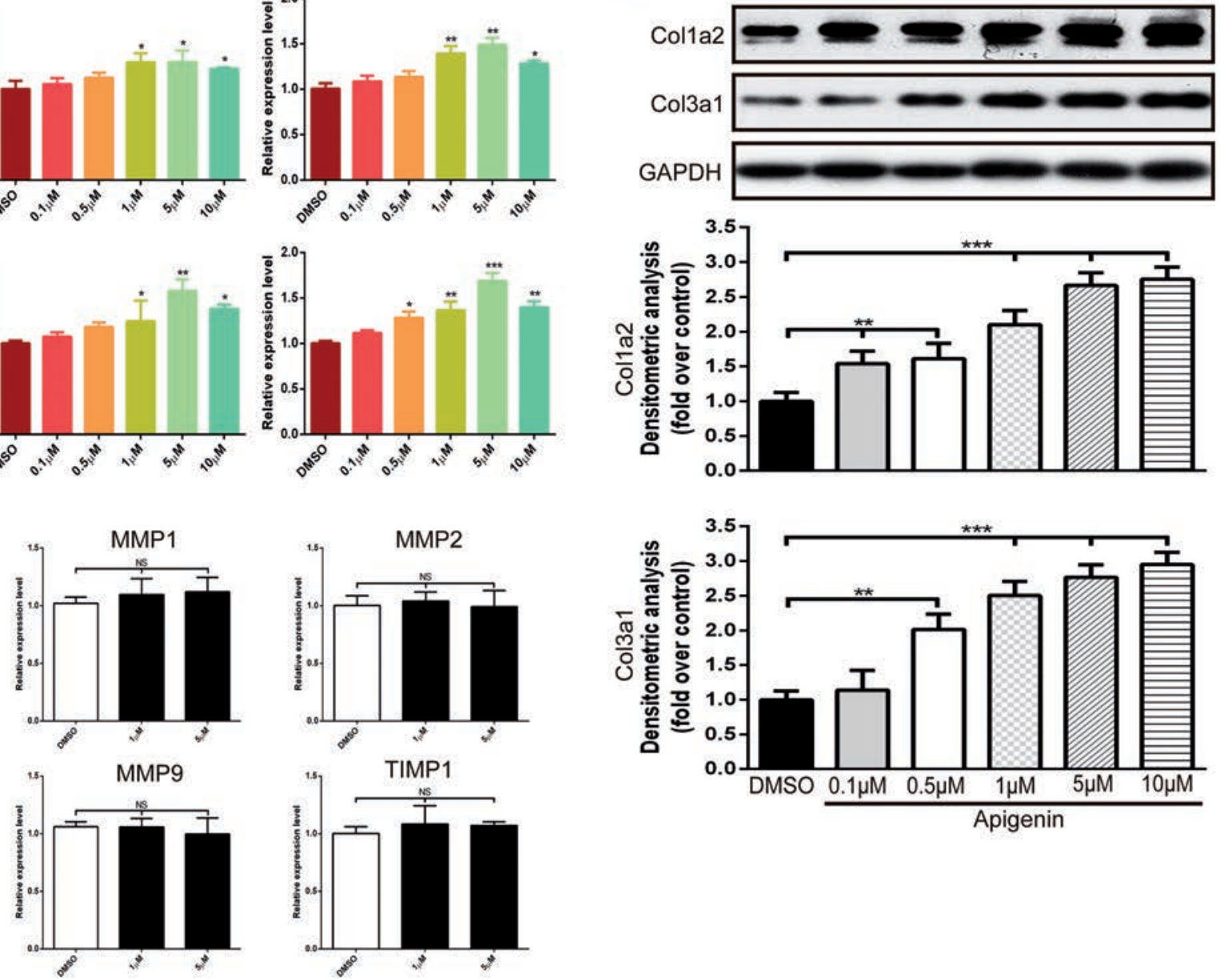

Figure 1. Apigenin stimulated collagen synthesis of fibroblasts. A) The molecular structure of apigenin. B) Toluidine blue staining in NIH/3T3 and HDFs for 5 days. C) Dose-dependent effects of apigenin on mRNA expression of Col1a2 and Col3al in NIH/3T3 and HDFs for 3 days. D) The protein level of Col1a2 and Col3a1 was measured by Western Blot at 5 days after apigenin was applied at concentrations of $0.1 \mu \mathrm{mol} / \mathrm{L}$ to $10 \mu \mathrm{mol} / \mathrm{L}$. E) The expression of MMP1, MMP2, MMP9 and TIMP1 were also assessed by real-time PCR. Data are presented as mean $\pm S D, n \geq 3$; NS, not significant; ${ }^{*} \mathbf{P}<0.05 ;{ }^{* *} \mathbf{P}<0.01 ; * * * P<0.001$. 
synthesis of extracellular matrix was increased. ${ }^{13}$ Further real-time PCR analysis showed that, in NIH/3T3 and HDFs, apigenin $(0.1 \mu \mathrm{mol} / \mathrm{L}$ - $10 \mu \mathrm{mol} / \mathrm{L})$ dose-dependently stimulated endogenous expression of Colla2 and Col3al. The most significant changes were observed when $\mathrm{NIH} / 3 \mathrm{~T} 3$ and HDFs were treated with apigenin at the concentration of 5 $\mu \mathrm{mol} / \mathrm{L}$, and the increase of Col3al was more obvious than Colla2 (Figure 1C). These upregulation effect of apigenin on collagen expression were then confirmed by Western blot analysis. When HDFs were treated with apigenin for 5 days, the protein level of Colla2 and Col3al were higher than that of cells treated with DMSO (Figure 1D). In addition, we next examined the effect of apigenin on matrix metalloproteinases (MMPs) and
A

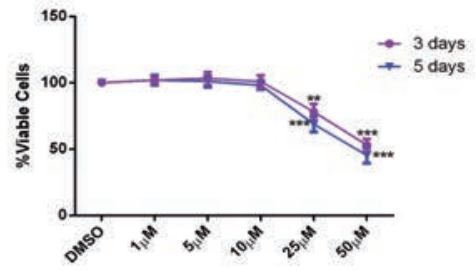

B

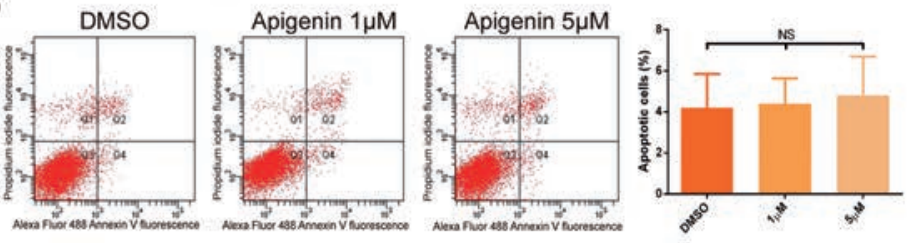

C
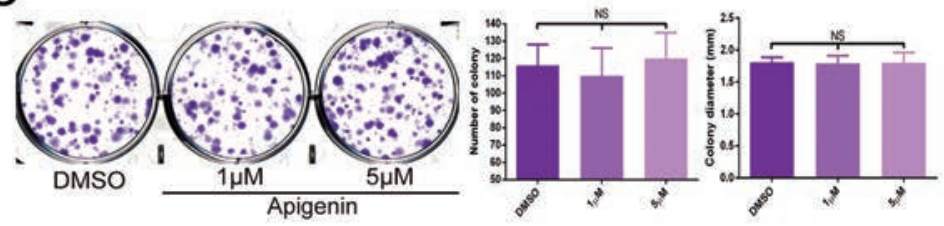

D
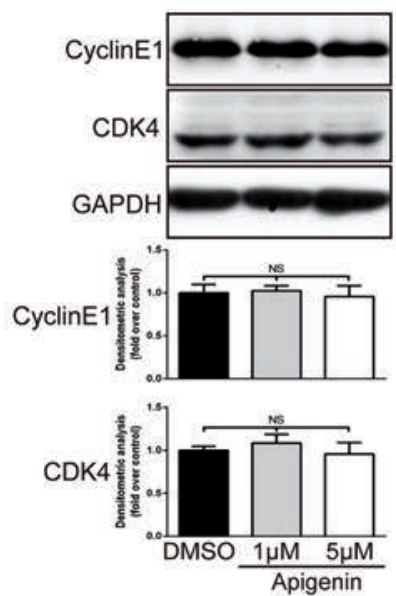

E

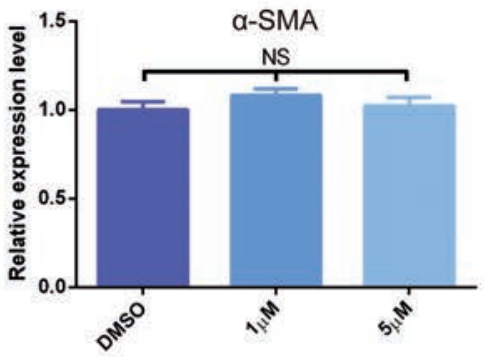

F

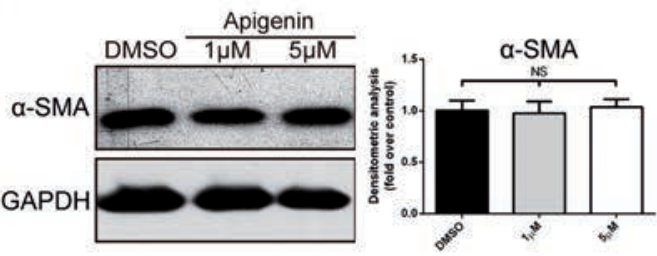

G

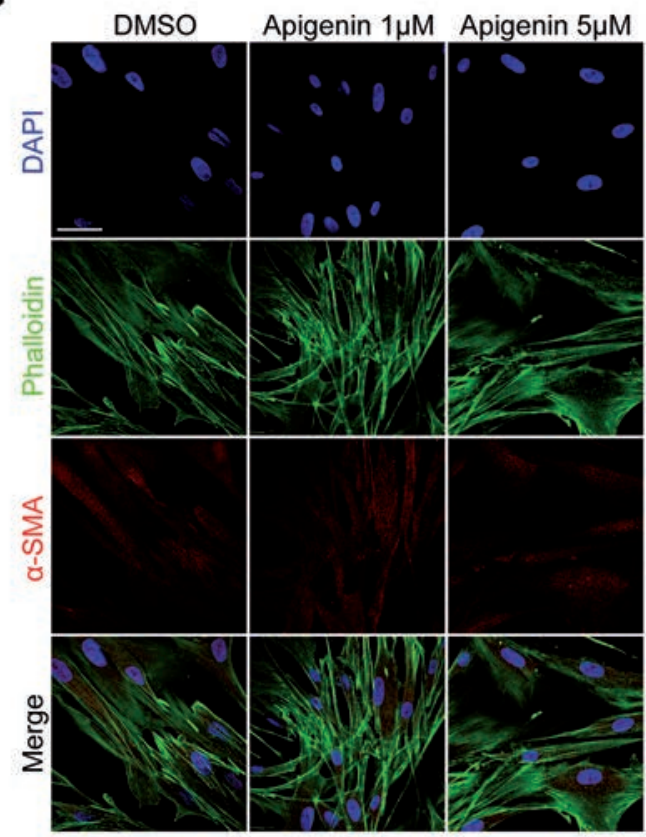

Figure 2. No obvious cytotoxicity exerted by apigenin on fibroblasts viability, apoptosis, proliferation, cell cycle and activation. A) Cell viability was examined by MTT assays at 3 or 5 days after apigenin was applied in HDFs. B) Apoptosis was evaluated after treating HDFs with $5 \mu \mathrm{mol} / \mathrm{L}$ or $1 \mu \mathrm{mol} / \mathrm{L}$ apigenin or DMSO; flow cytometry profile represents Alexa Fluor ${ }^{\circledR} 488$ Annexin V staining in X axis and PI in Y axis. C) The effect of apigenin on fibroblasts growth was investigated by monolayer colony formation assay. D) The expression of cyclin E1, CDK4, cyclin D1, CDK2 and p-CDK2 proteins was analysed using Western blot in HDFs. E-F) The levels of $\alpha$-SMA mRNA and protein expression were measured by real-time PCR and Western blot. G) Immunofluorescence cell staining for $\alpha$ SMA and F-actin in cultured HDFs after incubation with apigenin or DMSO for $72 \mathrm{~h}$; F-actin is shown by green fluorescence and $\alpha$ SMA is shown by red fluorescence; nucleus (blue) was stained with DAPI; scale bar: $50 \mu \mathrm{m}$. Data are presented as mean \pm SD, $\geq 3$; NS, not significant; ${ }^{* *} \mathrm{P}<0.01 ;{ }^{* * *} \mathrm{P}<0.001$. 
TIMP1, well-known proteases that degrade collagen proteins. The expression of MMP1, MMP2, MMP9, and their inhibitor TIMP1 were unchanged (Figure 1E).

\section{Apigenin did not effect fibroblasts viability and activity}

Afterwards, we studied the effect of apigenin on fibroblasts viability, apoptosis, proliferation and activation. In vitro, MTT assays showed that the viability of HDFs was similar with those incubated with DMSO, when incubated with apigenin ( 1 to $10 \mu \mathrm{mol} / \mathrm{L})$ for 3 or 5 days, respectively (Figure 2A). In addition, no significant differences in percentages of apoptotic cells was observed after the exposure of fibroblasts to apigenin (Figure 2B). To investigate the effects of apigenin on proliferation and cell cycle, colony formation assay and Western Blot analysis of cell cycle related proteins were performed. Colony forming ability of HDFs was similar in apigenin-treated group to DMSO-treated group (Figure 2C). The expression levels of cell cycle associated proteins remained unchanged between apigenin and DMSO treated groups (Figure 2D). These results suggested that apigenin had no obvious cytotoxicity on fibroblasts' viability, apoptosis and proliferation.

Fibroblast overactivation leads to pathological collagen deposition or scar formation. ${ }^{17}$ Myofibroblasts, known as activated fibroblasts, are marked by $\alpha$-SMA expression. To determine the effects of apigenin on fibroblasts' activation, we evaluated the levels of $\alpha$-SMA mRNA and protein expression (Figure 2 E,F) in cultured HDFs treated with apigenin. We found that $\alpha$-SMA mRNA expression had no obvious change in apigenin-treated cells compared with DMSO-treated cells. We also showed that apigenin did not affect $\alpha$-SMA expression in vitro by immunofluorescence staining (Figure 2G). These findings suggested that apigenin did not cause fibroblasts to overactivate into myofibroblasts while collagen synthesis was increasing.

\section{Induction of collagen synthesis was mediated by smad2/3 activation}

To further explore the underlying mechanism of how apigenin activated type-I and type-III collagen gene expression, transforming growth factor beta 1 (TGF- $\beta 1$ ) and mitogen-activated protein kinase (MAPK) signaling pathway were analysed. TGF- $\beta 1$ is a prototypic fibrogenic cytokine, enhancing extracellular matrix gene expression. Previous studies proved that Colla2 and Col3al were direct TGF- $\beta 1 /$ smad3 targets in human dermal fibroblasts. ${ }^{18}$ As shown in Figure $3 \mathrm{~A}$, when HDFs were treated for $12 \mathrm{~h}$, apigenin (1 $\mu \mathrm{mol} / \mathrm{L}$ or $5 \mu \mathrm{mol} / \mathrm{L}$ ) markedly increased the expression of phosphorylated smad2 and smad3 in a dose-dependent manner, whereas total smad2, smad3 and smad4 did not obviously alter. It also showed that apigenin had sustained effect on promoting phosphorylation of smad2 and smad3 after a 3-day treatment (Figure 3B). Yoon et al. ${ }^{19}$ revealed that MAPK pathway was involved with peptide-induced collagen synthesis of fibroblasts. However, when fibroblasts were treated with apigenin for $12 \mathrm{~h}$, the expression of total and phosphorylated JNK, ERK and p38 protein remained unchanged, compared with DMSO (Figure 3C). Immunofluorescence experiments demonstrated that after treatment with apigenin for $12 \mathrm{~h}$, smad3 protein (labeled by green) was significantly increased and mostly translocated into the nucleus (labeled by blue) (Figure 3D). By contrast, in the DMSO groups, smad3 were retained in the cytoplasm. Once targeted knockdown smad2/3 by specific siRNA, the upregulation effect of apigenin on the expression of collagen type-I and type-III protein was obviously reduced (Figure 3E), which confirmed that $s m a d 2 / 3$ is required for the transduction of apigenin effect on collagen expressions.

\section{Apigenin stimulated collagen syn- thesis in the D-galactose-induced skin aging mouse model}

The in vivo effects of apigenin on collagen synthesis was investigated in the D-galactoseinduced skin aging mouse model. The collagen expression was showed by H\&E, Masson's trichrome stain, Picrosirius red stain and immunohistochemistry. Histology showed significant changes in dermal thickness and density in samples obtained from D-gal-treated mice compared with PBS control group (Figure 4 A-D). After 1 month of apigenin administration at the concentration of 5 $\mu \mathrm{mol} / \mathrm{L}$, the mice exhibited obviously increased dermal thickness and collagen density compared with DMSO-treated mice (Figure 4 A-D). Magnified images showed that dermis in the apigenin-treated group exhibited compact and clearly evident staining, whereas collagens were loosely distributed in DMSO-treated dermis of the aging skin model (Figure 4 A-D), in both Masson's trichrome stain, Picrosirius red stain and immunohistochemistry examinations. Dermal collagen could be subdivided into type I and type III collagen after Picrosirius red staining under polarized light. As shown in Figure 4F, apigenin could significantly increase both collagen type I and type III density in the dermis of the skin aging mouse model. Quantitative data of dermal thickness and collagen density showed that mice subcutaneously injected with D-gal showed thinner skin and less collagen compared to control mice and apigenintreated mice demonstrated significantly thick- er and compact dermis (Figure $4 \mathrm{E}, \mathrm{F}$ ). The in vivo study also demonstrates that apigenin does not show any effect on activation of fibroblasts (Figure 4G).

\section{Discussion}

Dermal atrophy is the major causes of aging appearance. ${ }^{20}$ In vivo and in vitro studies show that decline in the production of collagen in aging fibroblasts is mainly responsible for decreasing in dermal thickness seen in extrinsically aging skin, which reveals dermal atrophy, fragmentation, and irregular collagen bundles..$^{21}$ Since the 70 s, animal and human derived collagens have been studied for soft tissue augmentation. ${ }^{22}$ Injectable filling implants are now widely used for cosmetic purposes. However, exogenic injectable collagen often presented various complications such as allergy, ecchymosis, local necrosis and infections of bacteria or virus. Scientists have tried for decades to find other alternative to stimulate endogenous collagen synthesis. There are several anti-oxidants, such as vitamins $\mathrm{C}$ and $\mathrm{E}$, co-enzyme $Q_{10}$ and retinoids used for treating UV-induced skin aging and wrinkles. ${ }^{23,24}$ However, only few compounds are able to induce type I collagen synthesis ${ }^{25-27}$ and none of them can stimulate both type I and type III collagen synthesis according to the record in literatures.

Apigenin, a plant flavone, has gained considerable attention due to its health benefits, chemopreventive properties and wide distribution in the plant kingdom..$^{28}$ Many studies have demonstrated that apigenin possesses a wide range of biological activities to the skin. It has been reported that apigenin can stimulate nucleotide excision repair genes to protect skin keratinocytes ${ }^{29}$ against UVB-induced skin inflammation. ${ }^{30}$ Dietary apigenin attenuates the development of atopic dermatitis-like skin lesions in atopic dermatitis model. ${ }^{31}$ Apigenin could also effectively reduce the incidence and size of skin tumors caused by ultraviolet B (UVB) exposure through the enhancement of UVB-induced apoptosis. ${ }^{32}$ In this study, we investigated the effect of apigenin on dermal fibroblasts' function.

At first, we found apigenin could increase the mRNA expression of Colla2 and Col3al in NIH/3T3 and HDFs. With extracellular matrix staining and Western Blot analysis, the stimulative effect of collagen on protein level was more significant. Although as reported in the literature, basal levels of Collal and $\alpha$-SMA mRNAs were reduced in fibroblasts treated with high concentration of apigenin (20 $\mu \mathrm{mol} / \mathrm{L}),{ }^{33}$ our research confirmed that apigenin of $25 \mu \mathrm{mol} / \mathrm{L}$ showed obvious cytotoxici- 
A

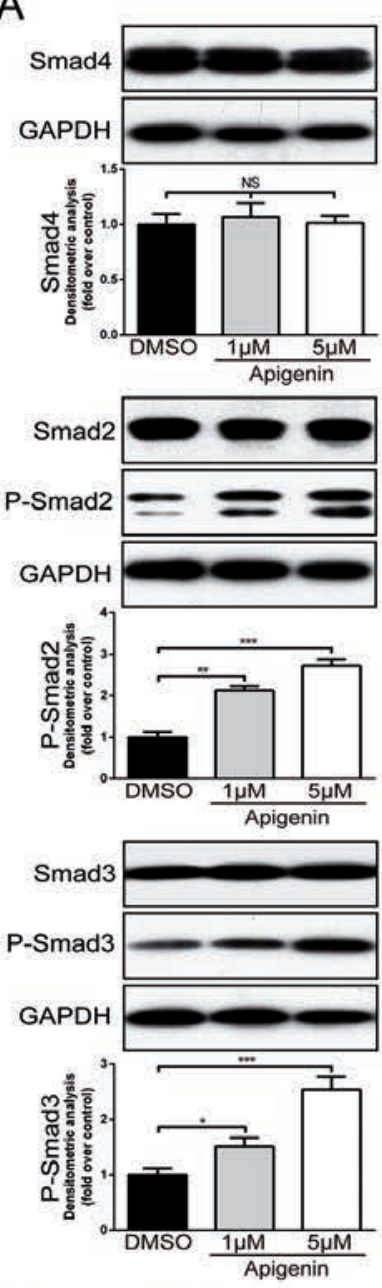

B
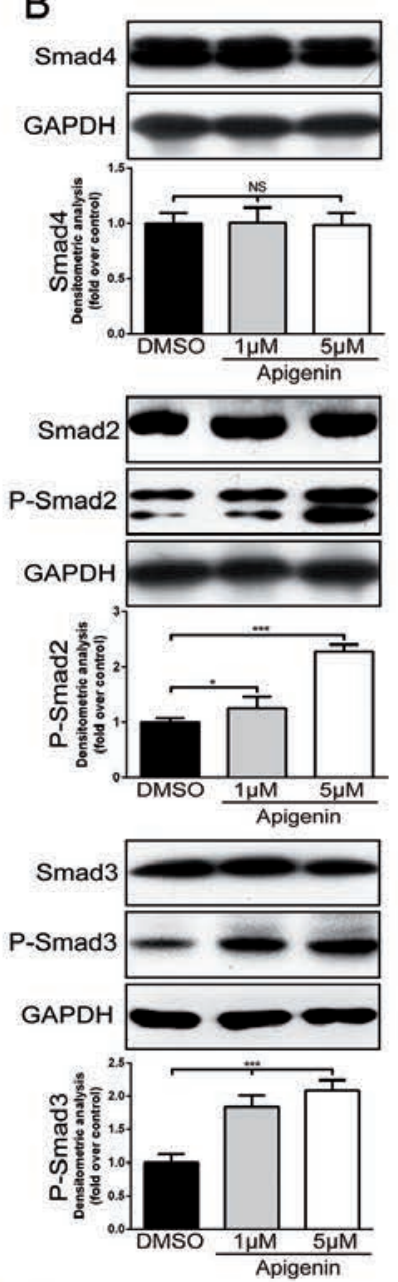

D

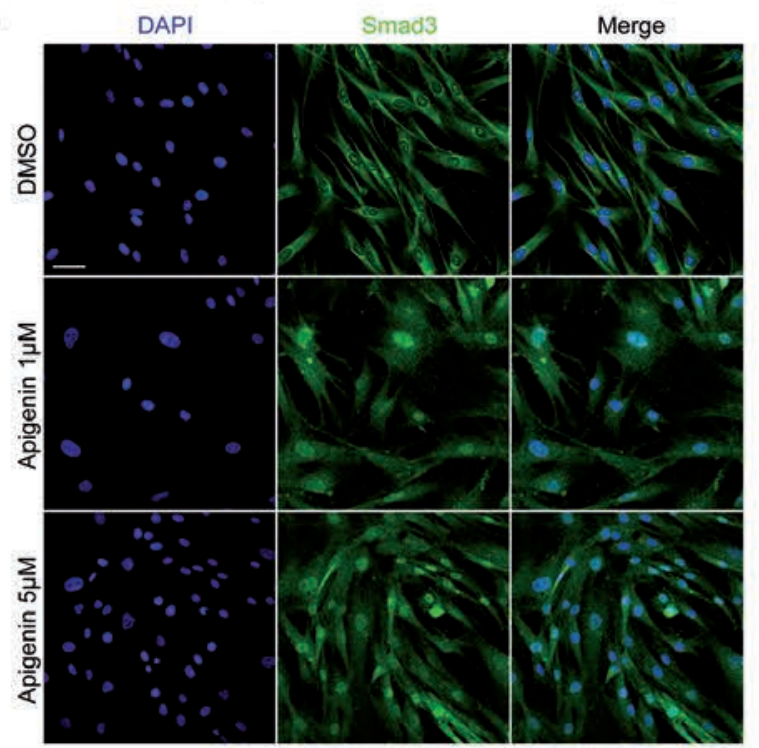

C

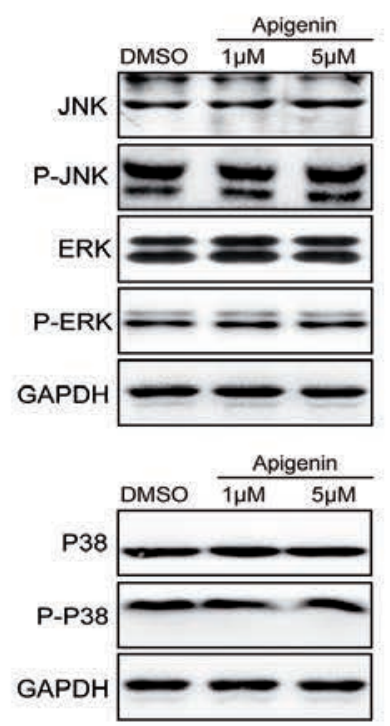

E
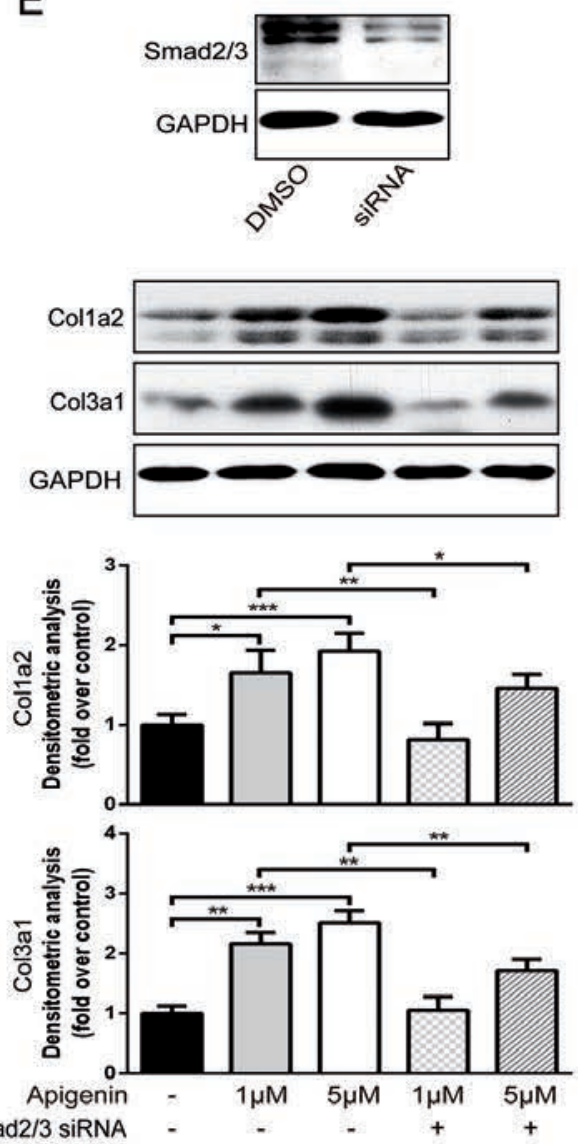

Figure 3. Apigenin-mediated collagen synthesis increase via smad2/3 signaling pathway. A,B) Western blot analysis and quantification of phosphorylated and total smad2, smad3 and total smad4 in HDFs with or without apigenin stimulation for $12 \mathrm{~h}$ or 3 days. C) Western Blot analysis of JNK, ERK and p38 in HDFs with or without apigenin stimulation for $12 \mathrm{~h}$. D) Immunofluorescence experiments: smad3 was labeled as green; nucleus (blue) was stained with DAPI; scale bar: $50 \mu \mathrm{m}$. E) Western blot showed the expression of Col1a2 and Col3a1 in HDFs when cells were treated with DMSO, apigenin or apigenin with specific siRNA of smad2/3. Data are presented as mean $\pm \mathrm{SD}, \mathrm{n} \geq 3$; NS, not significant; ${ }^{*} \mathrm{P}<0.05$; ${ }^{* *} \mathrm{P}<0.01$; ${ }^{* * *} \mathrm{P}<0.001$. 
A

B

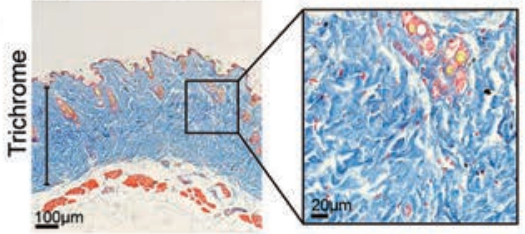

C

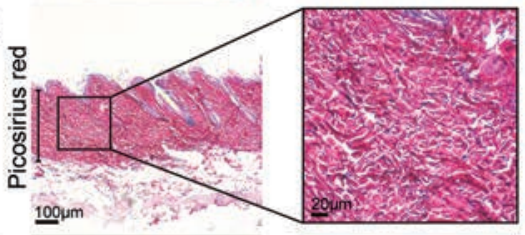

D

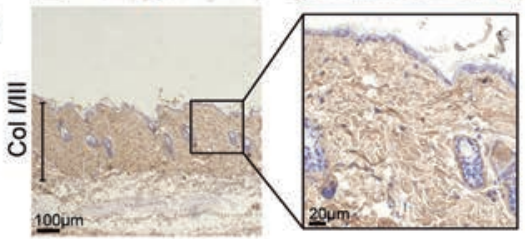

DMSO+D-gal
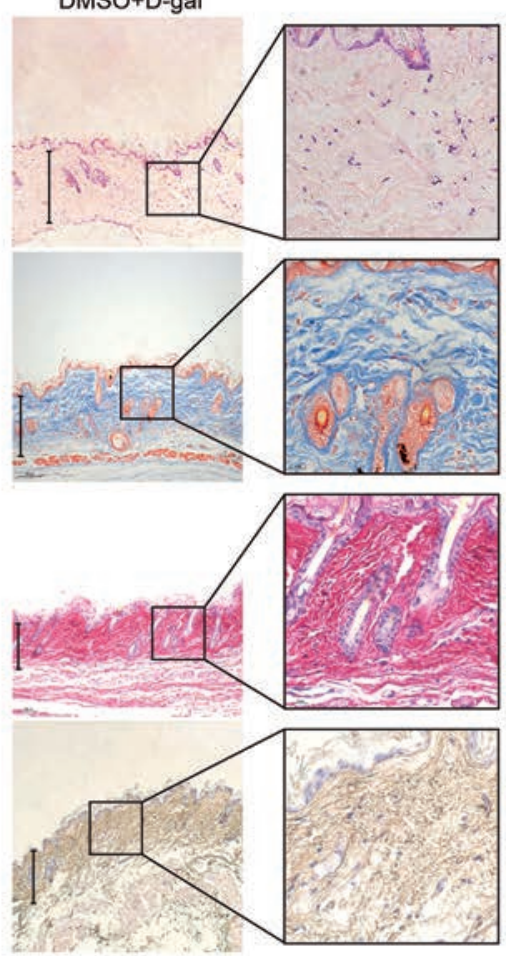

Apigenin+D-gal
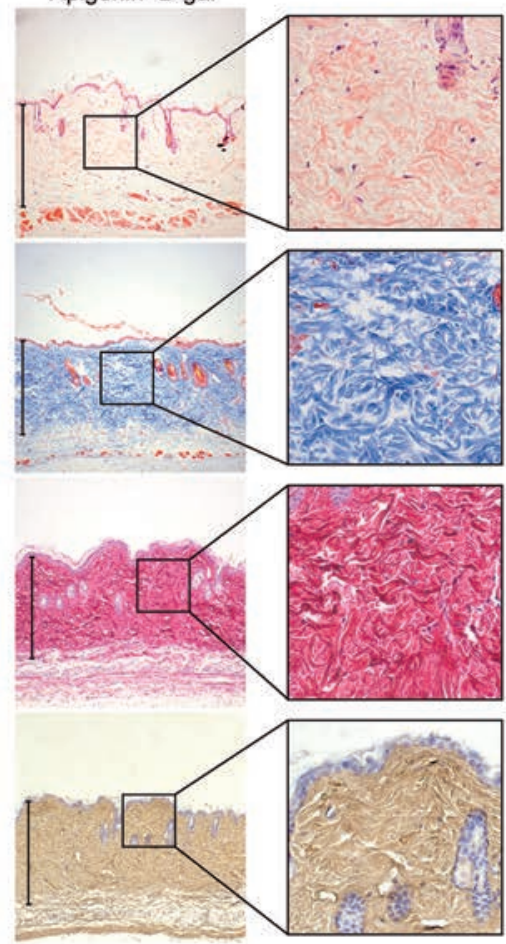

E

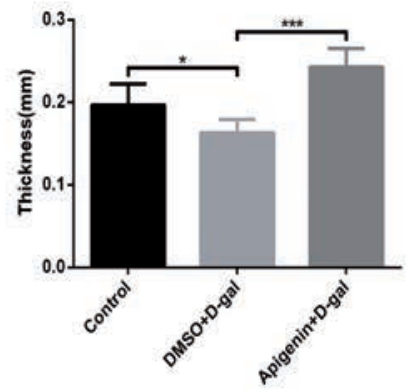

F
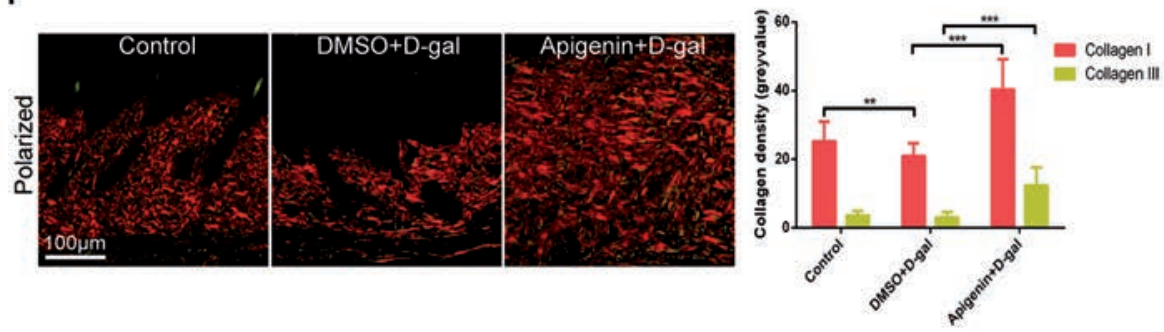

G

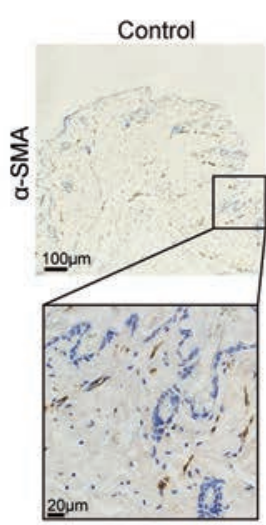

DMSO+D-gal

Apigenin+D-gal
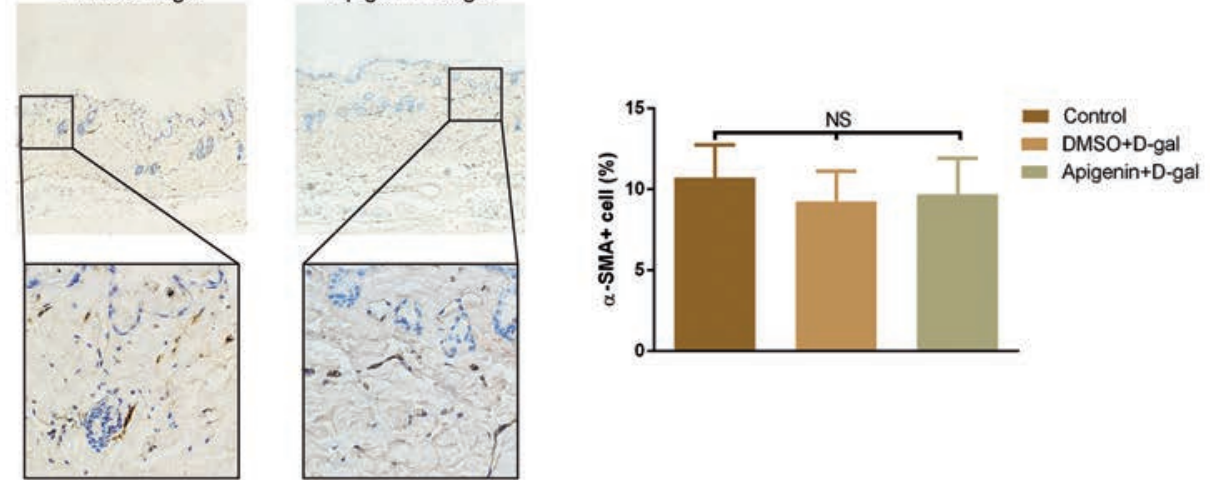

Figure 4. Apigenin increased dermal thickness and collagen density in the D-galactose-induced skin aging mouse model. A-D) H\&E, Masson's trichrome, Picrosirius red and immunohistochemistry stained dermis of control mice and D-gal-treated mice respectively received apigenin and DMSO; scale bars: $100 \mu \mathrm{m}$; zoom scale bars: $20 \mu \mathrm{m}$. E) Quantification of dermal thickness. F) Picrosirius red staining under polarized light and quantification of type I and type III collagen density; collagen type I is shown as red fibers and collagen type III is shown as green fibers; scale bars: $100 \mu \mathrm{m}$. G) Immunohistochemistry staining of $\alpha$-SMA of control mice and D-galtreated mice respectively received apigenin and DMSO; scale bars: $100 \mu \mathrm{m}$; zoom scale bars: $20 \mu \mathrm{m}$. Data are presented as mean \pm SD, $\mathrm{n}=6 / 6 / 6 ;{ }^{*} \mathrm{P}<0.05 ;{ }^{* *} \mathrm{P}<0.01 ;{ }^{* * *} \mathrm{P}<0.001$. 
ty in fibroblasts. We believed that the attenuating effect of high concentration of apigenin on phenotypic transitions in the analyzed cell populations were not independent of its cytotoxic activity. We detected the markers related to extracellular matrix degradation and found that apigenin had no effect on the balance of MMPs/TIMPs.

We further observed that apigenin directly activated smad2/3-dependent signaling pathway. This is not surprising since this flavonoid displays considerable muti-effect. It targets a number of secondary messengers, including those potentially involved in TGF- $\beta 1$ signaling pathway, such as NF-kB, ${ }^{34}$ MAPK/ERK, ${ }^{35}$ FAK, ${ }^{36,37}$ PKC $^{38}$ and PI3K-Akt ${ }^{39}$ in a cell contextdependent manner. We observed that apigenin markedly increased the expression of phosphorylated smad2 and smad3 protein, while total smad2, smad3 and smad4 protein all remained unaltered. So, a more meticulous network may connect TGF- $\beta 1$ signaling pathway and the abovementioned secondary messengers.

A previous study showed the accelerated aging effect of D-gal injection on mouse skin, as well as changes in dermal thickness and collagen content. ${ }^{15}$ In order to confirm the effect of apigenin on collagen synthesis in vivo, the D-galactose-induced skin aging mouse model was established. Our data indicated that skin aging mice treated with apigenin showed markedly increasing dermal thickness and collagen expression, compared with DMSO-treated mice. Hou et al. ${ }^{40}$ reported that topical apigenin improved epidermal permeability barrier function by stimulating epidermal differentiation, lipid synthesis and secretion, as well as cutaneous antimicrobial peptide production, and our result showed that dermal injection of apigenin significantly increased dermal thickness and density. So we could conclude that apigenin caused different biological functions with two forms of drug administration by acting on epidermis or derma, which might indicate the importance of choosing suitable administration methods to different skin diseases, even for the same drug.

Our study demonstrates that apigenin could induce both type I and type III collagen synthesis of fibroblasts in vitro and could increase dermal thickness and collagen deposition in the dermis of mice. This compound is a potential target for drug design and development for esthetic and reconstructive purpose.

\section{References}

1. Baumann L, Kaufman J, Saghari S. Collagen fillers. Dermatol Ther 2006;19: 134-40.
2. Fisher GJ, Wang ZQ, Datta SC, Varani J, Kang S, Voorhees JJ. Pathophysiology of premature skin aging induced by ultraviolet light. N Engl J Med 1997;337:1419-28.

3. Liang JA, Pei XR, Zhang ZF, Wang N, Wang JB, Li Y. The Protective Effects of LongTerm Oral Administration of Marine Collagen Hydrolysate from Chum Salmon on Collagen Matrix Homeostasis in the Chronological Aged Skin of SpragueDawley Male Rats. J Food Sci 2010;75: H230-8.

4. Hou H, Li BF, Zhang ZH, Xue CH, Yu GL, Wang JF, et al. Moisture absorption and retention properties, and activity in alleviating skin photodamage of collagen polypeptide from marine fish skin. Food Chem 2012;135:1432-9.

5. Matsuda N, Koyama YI, Hosaka Y, Ueda H, Watanabe T, Araya T, et al. Effects of ingestion of collagen peptide on collagen fibrils and Glycosaminoglycans in the dermis. $\mathrm{J}$ Nutr Sci Vitaminol (Tokyo) 2006;52:211-5.

6. Iannitti T, Morales-Medina JC, Coacci A, Palmieri B. Experimental and Clinical Efficacy of Two Hyaluronic Acid-based Compounds of Different Cross-Linkage and Composition in the Rejuvenation of the Skin. Pharm Res Epub 2014 Jun 25.

7. Sharma H, Kanwal R, Bhaskaran N, Gupta S. Plant flavone apigenin binds to nucleic acid bases and reduces oxidative DNA damage in prostate epithelial cells. PLoS One 2014;9:e91588.

8. Wang J, Liu YT, Xiao L, Zhu L, Wang Q, Yan T. Anti-Inflammatory Effects of Apigenin in Lipopolysaccharide-Induced Inflammatory in Acute Lung Injury by Suppressing COX2 and NF-kB Pathway. Inflammation 2014;37:2085-90.

9. Polier G, Giaisi M, Kohler R, Muller WW, Lutz C, Buss EC, et al. Targeting CDK9 by wogonin and related natural flavones potentiates the anti-cancer efficacy of the Bcl-2 family inhibitor ABT-263. Int J Cancer 2015;136:688-98.

10. Taupin P. Apigenin and related compounds stimulate adult neurogenesis. Mars, Inc., the Salk Institute for Biological Studies: W02008147483. Expert Opin Ther Pat 2009;19:523-7.

11. Lodhi S, Singhai AK. Wound healing effect of flavonoid rich fraction and luteolin isolated from Martynia annua Linn. on streptozotocin induced diabetic rats. Asian Pac J Trop Med 2013;6:253-9.

12. Singer AJ, Clark RA. Cutaneous wound healing. N Engl J Med 1999;341:738-46.

13. Yano F, Hojo H, Ohba S, Fukai A, Hosaka Y, Ikeda T, et al. A novel disease-modifying osteoarthritis drug candidate targeting Runxl. Ann Rheum Dis 2013;72:748-53.

14. Jin H, Wang X, Ying J, Wong AH, Cui Y,
Srivastava G, et al. Epigenetic silencing of a $\mathrm{Ca}(2+)$-regulated Ras GTPase-activating protein RASAL defines a new mechanism of Ras activation in human cancers. Proc Natl Acad Sci U S A 2007;104:12353-8.

15. Zhang S, Dong Z, Peng Z, Lu F. Anti-aging effect of adipose-derived stem cells in a mouse model of skin aging induced by $\mathrm{D}$ galactose. PLoS One 2014;9:e97573.

16. Prausnitz MR. Microneedles for transdermal drug delivery. Adv Drug Deliv Rev 2004;56:581-7.

17. Wang J, Dodd C, Shankowsky HA, Scott PG, Tredget EE, Wound Healing Research G. Deep dermal fibroblasts contribute to hypertrophic scarring. Lab Invest 2008; 88:1278-90.

18. Verrecchia F, Chu ML, Mauviel A. Identification of novel TGF-beta/Smad gene targets in dermal fibroblasts using a combined cDNA microarray/promoter transactivation approach. J Biol Chem 2001;276:17058-62.

19. Yoon JH, Kim J, Lee H, Kim SY, Jang HH, Ryu SH, et al. Laminin peptide YIGSR induces collagen synthesis in Hs27 human dermal fibroblasts. Biochem Biophys Res Commun 2012;428:416-21.

20. Fenske NA, Lober CW. Structural and functional changes of normal aging skin. J Am Acad Dermatol 1986;15:571-85.

21. Lavker RM. Structural alterations in exposed and unexposed aged skin. J Invest Dermatol 1979;73:59-66.

22. Klein AW, Elson ML. The history of substances for soft tissue augmentation. Dermatol Surg 2000;26:1096-105.

23. Kwok HH, Yue PYK, Mak NK, Wong RNS. Ginsenoside Rb-1 induces type I collagen expression through peroxisome proliferator-activated receptor-delta. Biochem Pharmacol 2012;84:532-9.

24. Winterfield L, Cather J, Cather J, Menter A. Changing paradigms in dermatology: Nuclear hormone receptors Clin Dermatol. 2003;21:447-54.

25. Lee J, Jung E, Yu H, Kim Y, Ha J, Kim YS, et al. Mechanisms of carvacrol-induced expression of type I collagen gene. J Dermatol Sci 2008;52:160-9.

26. Choi MS, Yoo MS, Son DJ, Jung HY, Lee $\mathrm{SH}$, Jung JK, et al. Increase of collagen synthesis by obovatol through stimulation of the TGF-beta signaling and inhibition of matrix metalloproteinase in UVB-irradiated human fibroblast. J Dermatol Sci 2007;46:127-37.

27. Wang J, Zhou J, Zhang N, Zhang X, Li Q. A heterocyclic molecule kartogenin induces collagen synthesis of human dermal fibroblasts by activating the smad4/smad5 pathway. Biochem Biophys Res Commun 2014;450:568-74. 
28. Shukla S, Gupta S. Apigenin: a promising molecule for cancer prevention. Pharm Res 2010;27:962-78.

29. Das S, Das J, Paul A, Samadder A, KhudaBukhsh AR. Apigenin, a bioactive flavonoid from Lycopodium clavatum, stimulates nucleotide excision repair genes to protect skin keratinocytes from ultraviolet B-induced reactive oxygen species and DNA damage. J Acupunct Meridian Stud 2013;6:252-62.

30. Byun S, Park J, Lee E, Lim S, Yu JG, Lee SJ, et al. Src kinase is a direct target of apigenin against UVB-induced skin inflammation. Carcinogenesis 2013;34:397-405.

31. Yano S, Umeda D, Yamashita S, Yamada K, Tachibana H. Dietary apigenin attenuates the development of atopic dermatitis-like skin lesions in NC/Nga mice. J Nutr Biochem 2009;20:876-81.

32. Abu-Yousif A0, Smith KA, Getsios S, Green KJ, Van Dross RT, Pelling JC. Enhancement of UVB-induced apoptosis by apigenin in human keratinocytes and organotypic keratinocyte cultures. Cancer Res 2008;68:3057-65.

33. Ricupero DA, Poliks CF, Rishikof DC, Kuang PP, Goldstein RH. Apigenin decreases expression of the myofibroblast phenotype. FEBS Lett 2001;506:15-21.

34. Kang OH, Lee JH, Kwon DY. Apigenin inhibits release of inflammatory mediators by blocking the NF-kappaB activation pathways in the HMC-1 cells. Immunopharmacol Immunotoxicol 2011; 33:473-9.

35. Hwang YP, Oh KN, Yun HJ, Jeong HG. The flavonoids apigenin and luteolin suppress ultraviolet A-induced matrix metalloproteinase-1 expression via MAPKs and AP-1dependent signaling in $\mathrm{HaCaT}$ cells. $\mathrm{J}$ Dermatol Sci 2011;61:23-31.

36. Franzen CA, Amargo E, Todorovic V, Desai BV, Huda S, Mirzoeva S, et al. The Chemopreventive Bioflavonoid Apigenin Inhibits Prostate Cancer Cell Motility through the Focal Adhesion Kinase/Src Signaling Mechanism. Cancer Prev Res
(Phila) 2009;2:830-41.

37. Hu XW, Meng D, Fang J. Apigenin inhibited migration and invasion of human ovarian cancer A2780 cells through focal adhesion kinase. Carcinogenesis 2008;29:2369-76.

38. Balasubramanian S, Zhu L, Eckert RL. Apigenin inhibition of involucrin gene expression is associated with a specific reduction in phosphorylation of protein kinase C delta Tyr(311). J Biol Chem 2006;281:36162-72.

39. Shukla S, Gupta S. Apigenin-induced cell cycle arrest is mediated by modulation of MAPK, PI3K-Akt, and loss of cyclin D1 associated retinoblastoma dephosphorylation in human prostate cancer cells. Cell Cycle 2007;6:1102-14.

40. Hou M, Sun R, Hupe M, Kim PL, Park K, Crumrine $\mathrm{D}$, et al. Topical apigenin improves epidermal permeability barrier homoeostasis in normal murine skin by divergent mechanisms. Exp Dermatol 2013;22:210-5. 